\title{
NI ESCOLÁSTICOS NI JANSENISTAS: FILOSOFÍA MORAL EN EL NÁPOLES DE LA CONTRARREFORMA
}

\author{
POR \\ ADRIANA LUNA-FABRITIUS \\ University of Helsinki \\ adriana.fabritius@eui.eu
}

\begin{abstract}
RESUMEN
Este artículo revela elementos clave del mapa intelectual napolitano de la era de la Contrarreforma, que fue uno de los más complejos y fascinantes de la historia Italiana en los albores de la llustración. El objetivo es restablecer el lugar tanto del jansenismo como de la Escolástica para la historia intelectual napolitana de la primera mitad del siglo xvilI. Para ello, este artículo sitúa las Cartas dirigidas al Padre General del Compañía de Jesús (1731) del patricio genovés y filósofo político Paolo Mattia Doria en el contexto del juicio de la Inquisición a los ateístas-atomistas de 1688-1697, cuyos ecos se escucharon aún durante las primeras décadas del siglo XVIII.
\end{abstract}

PALABRAS CLAVE: Jansenismo, jesuitas, casuística, libre albedrío, escepticismo, epicureísmo, cartesianismo, heterodoxia religiosa, Nápoles, llustración, Contrarreforma

\section{NEITHER SCOLASTICS NOR JANESITS: MORAL PHILOSOPHY IN THE NAPLES OF THE COUNTER-REFORMATION ERA}

\begin{abstract} the first decades of the eighteenth Century. Enlightenment, Counter-Reformation.

$\begin{array}{ll}\text { Recibido/Received } & 19-12-2014 \\ \text { Aceptado/Accepted } & 22-01-2016\end{array}$
\end{abstract}

This article reveals key elements of the Neapolitan intellectual map of the Counter-Reformation one of the most complex and fascinating of the Italian history at the dawn of the Enlightenment. The main objective is to resettle the place of both Jansenism and Scholastics to the Neapolitan intellectual history of the first half of the eighteenth Century. This article places the Letters addressed to the Father General of the Society of Jesus written by the patrician Genoese and political philosopher Paolo Mattia Doria in the context of the Inquisition's trial against the atheists-atomists (1688-1697), whose echoes were heard all the way to

KEY WORDS: Jansenism, Jesuits, Casuistry, Free will, Scepticism, Epicureanism, Cartesianism, Religious heterodoxy, Naples,

INTRODUCCIÓN

En cartas dirigidas al General Superior de la compañía de Jesús, escritas alrededor de 1731, el patricio genovés establecido en Nápoles, Paolo Mattia Doria (1667-1746), no sólo definía su posición en relación con el debate en curso con respecto a la supremacía de jesuitas o jansenistas, sino que además manifestaba su preocupación sobre los peligros que corría la república si adoptase los fundamentos morales de cualquiera de estos grupos religiosos en el Nápoles de la Contrarreforma. ${ }^{1}$ Las Cartas eran en realidad siete

1 Doria se refiere al Reino de Nápoles aún bajo el dominio austriaco, pero República es sinónimo de Estado en ese momento. diálogos con los que Doria pretendía formar un libro con el título Lettere di Paolo Mattia Doria al Reverendissimo Padre Generale Della Compagnia di Gesù, ${ }^{2}$ al parecer muy al estilo, pero con un propósito distinto, al de las Lettres Provinciales

2 Doria, P. M. [1731] 1992. "Lettere di Paolo Mattia Doria al Reverendissimo Padre Generale della Compagnia di Ges. Nelle quali dop. narratagli una nera Calunnia pratticata contro l'Autore da i Gesuiti di Genova, se gli mostra, come s. fatte calunnie usate da i Gesuiti di Genova, se gli mostra, come s. fatte calunnie usate da i Gesuiti di Genova siano caggione da i gravissimi difetti di tutta la Compagnia di suo governo, e si prega di emendargli In questi Dialoghi poi si dimostra che i RR.PP. Gesuiti sono stati di danno ugualmente alla Repubblica che a S. Chiesa", en G. Belgioioso, (ed.), Manoscritti Napoletani: Vol. I, 231-400. Napoli: Galatina C. Editore. En adelante se citará esta obra como 1731. 
de Blaise Pascal (1656-1657). Mientras Pascal buscaba defender con su texto al jansenista Antoine Arnauld, Doria estaba interesado en discutir los principios fundacionales de las sectas religiosas - como él las llamaba - jesuitas y jansenistas. Sin embargo, la obra de Doria permaneció entre sus escritos inéditos consignados por él mismo antes de su muerte a la Biblioteca di Sant'Angelo a Nido en Nápoles, ciudad donde vivió hasta el final de su vida en $1746 .{ }^{3}$ Por su contenido, es fácil notar que el manuscrito doriano no estaba terminado y que su autor tenía intención de suprimir secciones enteras, que bien le hubieran valido más que una simple amonestación por parte de los censores eclesiásticos.

En la obertura, como era obligado en la época, Doria comenzaba haciendo acto de fe y reconociendo a la religión católica como la única y verdadera. Inmediatamente después, aclaraba que aquellos hombres de letras que afirmaban que los napolitanos se habían hecho seguidores de los autores de Port-Royal debido a su oposición a los jesuitas, se equivocaban rotundamente, ${ }^{4}$ ya que si bien en algún momento algunos cardenales habían distribuido en Nápoles algunas obras de Pascal y la Moral práctica de Arnauld, se sabe que lo hicieron para dar un marco de referencia a la moral relajada de los jesuitas, para exhibirlos, y no porque consideraran al jansenismo una opción viable para el reino napolitano. ${ }^{5}$

Por este preludio, todo parece indicar que la intención de Doria en estas Cartas era ensayar una filosofía moral que fuese más allá de los límites delineados por estos dos grupos religiosos y que, al parecer, representaban las antípodas en cuestiones de moral en su época. Asimismo, Doria quería llevar a cabo su empresa sin poner en riesgo los fundamentos de la sociedad que la religión católica garantizaba y con la que no tenía intención de entrar en controversia. ${ }^{6}$

En lo que sigue se presenta la manera en la que surge la necesidad de encontrar un nuevo paradigma filosófico a partir de los avances científicos de las academias napolitanas durante la revolución científica del siglo XVII en el sur de Italia; la labor del filósofo genovés Paolo Mattia Doria en la búsqueda de dicho paradigma a partir de la reconstrucción de su biografía intelectual; $y$, se introducen en detalle las críticas principales de la época a las comunidades jesuita y jansenista, a través de la reproducción de fragmentos del dialogo de Doria como aparece en las Cartas.

SOBRE LA NECESIDAD DE UN NUEVO PARADIGMA FILOSÓFICO: LOS NOVATORES NAPOLITANOS

Desde el punto de vista historiográfico, estas Cartas proporcionan información suficiente para entender dos fenómenos cruciales del pensamiento no sólo napolitano, sino italiano e incluso europeo del siglo XVIII propio de la

3 Los manuscritos inéditos han sido publicados por Belgioioso, G. 1992. Manoscritti Napoletani Napoli: Galatina Congedo Editore, 5 vols.

4 Doria, Paolo, M. 1731: 231.

5 Doria, Paolo, M. 1731: 336

6 Sobre ejemplos similares en la era de la contrarreforma véase Comparato, V. I. "El pensamiento político de la Contrarreforma y la Razón de Estado de Estado" en ese mismo volumen.
Contrarreforma. Las Cartas de Doria son testimonio de que ciertos fenómenos aparecen desde principios de la década de los treinta, a pesar de que la historiografía ha datado su aparición más tarde, en plena llustración: por una parte, éstas develan información clave sobre el enfrentamiento entre los científicos experimentales y la curia romana durante la revolución científica en el sur de Italia. Esto es, del gran conflicto que tuvo lugar en el reino de Nápoles hacia finales del siglo XVII entre los miembros de la academia más prominente del sur de Italia en ese periodo - que reunía a los hombres de letras, juristas, médicos anatomistas y algunos de los atomistas más destacados del sur de la península, a saber, la Accademia degli Investiganti y los defensores de la autoridad papal, los jesuitas, que pugnaron por su objetivo desde diferentes frentes y valiéndose de distintas estrategias desde el inicio de la era de la Contrarreforma. Por otra parte, los documentos que conforman las Cartas mejoran nuestro conocimiento sobre el lugar común que identificaba al jansenismo como la tradición moral dominante en el Reino de Nápoles durante los siglos XVII y XVIII. ${ }^{7}$ Estas Cartas nos muestran que, para algunos autores del setecientos napolitano, a pesar de lo que ha afirmado la historiografía, el jansenismo no podría ocupar el lugar que la probabilística estaba dejando vacante, al menos no a finales del siglo XVII y principios del XVIII. En conjunto, estos dos elementos nos permiten reconstruir la forma en que la casuística fue puesta en entredicho como método para ejercer justicia y como fundamento de la moral, del derecho y, principalmente, de la ciencia; por lo tanto, de la necesidad de dejar atrás la Escolástica para dar paso a un sistema confiable.

Por lo que respecta al primer punto, en realidad, lo ocurrido a finales del siglo XVII, más que una disputa entre académicos e inquisidores pertenecientes a la compañía de Jesús, en realidad fue un juicio contra los científicos napolitanos que duró algunas décadas y que concluyó con la condena y excomunión de algunos miembros de una de las academias más importantes para la llustración napolitana: la Accademia degli Investiganti, fundada en Nápoles al parecer en 1650 (formalmente en 1663) con el lema de Lucrecio Vestigia lustrat, ${ }^{8}$ y que era el símbolo de la renovación cultural, identificada como el centro de difusión del pensamiento de Galileo Galilei, Pierre Gassendi y, sobre todo, de René Descartes. ${ }^{9}$ Distinguidos juristas, literatos, anatomistas y científicos fueron sus fundadores, individuos que más tarde han sido reconocidos como piezas clave de

7 Capone, B. G. 1920. La filosofia francese e italiana del settecento II: 6 Arezzo: Pagine Critiche.

Jemolo, Arturo C. 1928. II giansenismo in Italia prima della Rivoluzione Bari: Laterza \& figli; Stella, P. 1966. Il giansenismo in Italia: I-II, Zurich: Pas Verlag.

8 La fecha de fundación es controversial. Maylander y Fisch coinciden en 1750 mientras que Carmine y Capucci afirman que fue en 1663; cfr., Maylender, M. 1926-1930. Storia delle Accademie d'Italia: vol. 3-267, 526 Bologna: L. Cappelli; C. Jannaco, y M. Capucci, 1963. II Seicento. Milano: F. Vallardi y M. H. Fisch, 1953. 'The Academy of the Investigators". en Sciene, Medicine and History: 521-526 London: Oxford University Press. Fisch afirma que la fecha de su organización formal pudo haber sido en 1663 y de ahí la confusión.

9 Di Capua, L. 1683. 'Il Volubile Accademico Investigante al lettore', en Lezioni intorno alla natura delle mofete, Nápoles. 
la revolución científica del siglo XVII en el sur de Italia, entre ellos estaban Leonardo di Capua (1617-1695), que cultivaba el derecho, la medicina y la ciencia, en línea con Galileo, Descartes y el experimentalismo de los 'modernos'; ${ }^{10}$ Tommaso Cornelio (1614-1684), quien estudió medicina en Roma pero que se desenvolvió sobre todo en el área de la investigación naturalista; ${ }^{11}$ Carlo Buragna (1634-1679), filósofo y científico, que escribió el prefacio a la obra de Lucretius (1683), el autor más influyente del momento; ${ }^{12}$ Luca Antonio Porzio (1639-1724), médico, filósofo y naturalista, cuyas investigaciones sobre todo en medicina militar, fueron cruciales en el contexto de la guerra entre el Sacro Imperio Romano y el Otomano y que le valieron el reconocimiento de Leopoldo I, quien hizo imprimir su obra; ${ }^{13}$ Marzio Carafa, duque de Maddaloni (1650-1703), que además de académico era un grande de España radicado en el reino de Nápoles; ${ }^{14}$ los destacados juristas Francesco (1625-1698) y Gennaro D’Andrea (1637-1710); el jurista de carrera, pero literato y lingüista por afición Niccolò Amenta (1659-1719), acreditado por ser un gasendista como su maestro di Capua; ${ }^{15}$ Fulvio Caracciolo; Antonio Monforte

10 Di Capua publicó en 1681 su famosa obra Parere donde exponía sus ideas sobre la investigación médica y científica que fue contestada por el Jesuita Giovanni de Benedictis (1622), conocido defensor de las teorías aristótelicas y adversario del atomismo y de las nuevas ideas de los jóvenes napolitanos, dando lugar al inicio del enfrentamiento entre científicos y jesuitas. cfr., Di Capua, L. 1683; Vitale, M. 1965. "Leonardo di Capua e il capuismo napoletano", in Acme XVII:95 y ss. Véase también: http://www.imss.fi.it/milleanni/cronologia/biografie/lecapua.html

11 Durante su vida Cornelio se ocupó de la investigación naturalista telesiana transmitida a Campanella por su mentor Marco Aurelio Severino. Se dedicó a la enseñanza de las matemáticas y medicina teórica en Nápoles. Fue el autor de la introducción a la obra de Descartes y Gassendi. En 1663 publicó Progymnasmata phisica, que ha sido considerada la síntesis de su investigación científica y teórica. Cfr. Mille anni di scienza in Italia, opera del Museo Galileo. Istituto Museo di Storia della Scienza di Firenze, y Addante, Luca. 2001. 'Tommaso Cornelio (16141686)', en Cosenza e i consentini: un volo lungo tre millenni. Soveria Mannelli: 58 Rubbettino Editore.

12 Buragna fue autor de varios escritos filosóficos y científicos que permanecieron inéditos o se perdieron. Entre los publicados están Commentari sul Timeo di Platone y Note sulle sezioni coniche di Apollonio Pergeo. Su prefacio a las Poesie latine e italiane de Lucrecio fue editado de forma póstuma en 1683.

13 Porzio destacó sobre todo en medicina y en medicina militar. Entre sus obras más importantes se encuentra De Militis in castris sanitate tuenda (1683) La primera edición fue editada por Leopoldo I en 1685 de forma póstuma, pero tuvo varias ediciones en Nápoles (1701, 1728), La Haya (1739) y Leiden (1741); fue traducida al francés en 1744 y al inglés en 1747. Sobre la importancia de sus experimentos médicos para la llustración Europea: Conforti, M. 2007, "chapter 4" en O. P. Grell y A. Cunningham (eds.). Medicine and Religion in Elightenment Europe. England: Ashgate Publishing y para la importancia de sus experimentos en medicina militar Sir G. Ballingall, 1833. "Outlines on the Course of Lectures on Military Surgery, delivered in the University of Edinburgh" en Edinburgh Medical and Surgical Journal 40: 438-458. Véase también Napoli-Signorelli, P. 1811. Vicende della Cultura nelle due Sicilie. Dalla venuta delle Colonie straniere sino a' nostri giorni: 267-268 Nápoles, 2a ed.; Martini, P. 1837. Biografia Sarda t. I: 17-18 Cagliari: Reale Stamperia; Giovanni, A. 1812. Dell'Origine de' progressi e dello Stato attuale d'ogni letteratura t. 14: 239-240 Prato: Stamperìa di Vincenzo Vestri.

14 Marzio Carafa era el séptimo duque de Maddaloni y el décimo conde de Cerrreto Sannita, caballero del Tonsón de Oro y Grande de España.

15 Entre las publicaciones de Niccolò Amenta están: 1710. Vita di Lionardo da Capua, en Vite degli Arcadi illustri II: Roma [hay otra edición
(1644-1717), uno de los matemáticos más importantes de Italia en este periodo; ${ }^{16}$ y el famoso escritor antibarroco y neopetrarquista Niccolò Caravita (1647-1717). ${ }^{17}$ Este último fue, de hecho, quien introdujo a los jóvenes Giovan Battista Vico (1668-1744), Paolo Mattia Doria, Costantino Grimaldi (1667-1750) y Pietro Giannone (1676-1748) al mundo cultural napolitano. Fue también Caravita quien convenció más tarde al duque de Medinacoeli de institucionalizar su tertulia en la Accademia Palatina.

Para algunos especialistas, a pesar de su supresión oficial en 1683, la actividad de la Accademia degli Investiganti puede ser rastreada hasta 1737 con varias interrupciones; ${ }^{18}$ mientras que para otros, la Academia terminó su actividad en 1683 sin mayores consecuencias. ${ }^{19}$ Según los defensores de la última hipótesis, después de su conclusión, sus miembros se unieron a diferentes grupos. ${ }^{20}$

Desde sus inicios la Accademia degli Investiganti fue muy reconocida por ser una de las primeras de su género en Italia, por haber discutido y enriquecido líneas de investigación europeas en áreas experimentales de filosofía natural ${ }^{21}$ y por su interacción con miembros de otras academias, como la Accademia del Cimento, que había sido fundada por los discípulos de Galileo en Florencia, y la Royal Society

que indica Venecia, pero Nápoles]; 1668. II Torto e'I Diritto del non si può, dato in giudizio sopra molte regole della lingua italiana, esaminato da Ferrante Longobardi Roma y de forma póstuma apareció en 1723 Della lingua nobile d'Italia e del modo di leggiadramente scrivere in essa non che di perfecto parlare, Nápoles. Amenta mantuvo una polémica contra el marinismo y fue purista en el campo lingüístico. Se le conoce como tradicionalista en el campo de la poesía y el teatro.

16 Monforte estudió filosofía en la Universidad de Nápoles con Leonardo Di Capua y cultivó las matemáticas que aprendió de T. Cornelio en la primera etapa de la Accademia degli Investiganti. Participó en la segunda a partir de 1695, reunida nuevamente por G. Gimma en la Accademia degli Spensierati di Rossano. De esta última pasó inmediatamente, en 1698, a la Academia Palatina del duque de Medinacoeli donde entró en contacto con Doria. En su investigación siguió siempre la tradición investiganti de trabajar con la astronomía y la física como aspectos de una misma investigación. Durante su vida mantuvo una estrecha relación con Antonio Magliabechi, quien fue su vínculo a los grandes debates italianos y europeos. Viajó a Constantinopla un par de veces donde se informaba de los debates matemáticos de aquella región. En vida publicó sus lecciones matemáticas: De syderum intervallis seu magnitudine (1699), De problematum determinatione, Nápoles, y, de forma póstuma, De Stellarum Motibu (1720). Cfr. Torrini, M. 1973. "Antonio Monforte uno scienziato tra l'Accademia degli Investiganti e quella palatina di Medinaceli", en Zambelli, P. Ricerche sulla cultura dell'Italia moderna: 109 Bari, Laterza; Favino, F. 2011 "Antonio Monforte" en Dizionario biografico degli Italiani, Trecani, ad vocem; Niccolini, F. 1941. Uomini di spada, di chiesa, di toga, di studio ai tempi di G.B. Vico, Milán: U. Hoepli.

17 Caravita escribió la introducción a la obra clave para la crítica literaria de finales del siglo XVII, Lettura sopra la concione di Marfisa a Carlo Magno de Gregorio Caloprese (1691); de él también cfr. [1695] 1709. Ragione a pro della fedelissima città e Regno di Napoli contr'al procedimento straordinario nelle cause del Sant'Officio, Nápoles, que fue colocada en el Index Librorum Prohibitorum en 1710 y Id., Niun diritto compete al sommo pontefice sul Regno di Napoli: dissertazione istoricalegale, Nápoles, y que también pasó al Index en 1714.

18 Fisch, M. H. 1953: 521-563.

19 Belgioioso, G. 2012. "Paolo Mattia Doria” en Dizionario biografico degli Italiani: ad vocem Roma: Istituto della Encliclopedia Italiana.

20 Algunos académicos sostinen que la actividad de la Academia degli Investiganti cesó por completo cuando fue suprimida la primera vez. Cfr. Ibídem.

21 Fisch, M. H. 1953: 540. 
de Londres. ${ }^{22}$ En correspondencia con sus aspiraciones, sus miembros se llamaban a sí mismos neotéricos: proponentes de nuevas ideas, sobre todo en los campos científico y médico. ${ }^{23}$ La de los Investiganti, al estar vinculada a los métodos experimentales de Galileo, Gassendi y Descartes, ha sido considerada una academia de corte antiaristotélico. Además de las ciencias y la medicina, algunos de sus miembros cultivaron estudios jurídicos y literarios; estos últimos, eran partidarios del regreso a la pureza de la poesía de Petrarca.

Los autores que han especulado sobre la continuidad de la Accademia degli Investiganti más allá de 1683, han señalado la existencia de reuniones informales, así como las de las Academias de los Spensierati di Rossano, la Palatina del duque de Medinacoeli (1698-1701) y la Arcadia, fundada en Nápoles en 1703, como parte de la vida intelectual de la Accademia degli Investiganti. Para sustentar su tesis han argumentado que estas academias recogieron no sólo algunos de sus miembros sino también la misión de los investiganti. ${ }^{24}$ No obstante, se echan en falta estudios que vinculen todas estas academias entre sí a lo largo del tiempo tomando la agenda intelectual y política de la academia como hilo conductor. La evidencia con la que se cuenta en la actualidad muestra que los miembros originarios se mantuvieron activos, aún después de la supresión oficial aunque no se reunieron formalmente o lo hicieron en distintos grupos, y que todos ellos alcanzaron un alto nivel de actividad nuevamente a partir de 1697. ${ }^{25}$

Ahora bien, la tesis de la continuidad de la academia se refuerza por el hecho de que a pesar de su supresión en 1683, en 1688 la Inquisición inició un proceso contra cuatro de sus miembros originarios. El proceso se conoce como el juicio de los ateístas y estaba dirigido contra Filippo Belli, el matemático Giacinto de Cristofaro (1664-1725), ${ }^{26}$ el poeta

22 Con algunos miembros la comunicación era directa, mientras que con algunos otros la relación era mediada por el influyente bibliotecario de Leopoldo de' Medici y miembro de la Respublica literaria, Antonio Magliabechi (1633-1714). Cfr. Mirto, A. 2012. Lettere di Antonio Magliabechi a Leopoldo de' Medici, Roma: Aracne.

${ }^{23}$ El término neotérico era designado para un grupo completo de personas que compartían el rechazo a normas tradicionales y la búsqueda de nuevas formas y contenidos, y, aunque parezca paradójico, la cultura Helenística los proveyó con puntos de referencia importantes para su renovación.

${ }^{24}$ Cfr. Gimma, G. 1703. Elogi accad. Della società degli Spensierati di Rossano I: 160 y ss Nápoles. Crescimbeni, G. M. 1720. Notizie istoriche degli arcadi morti I: 218 y ss. Roma: Nella Stamperia di Antonio de Rossi; Carini, Isidoro. 1891. L'Arcadia dal 1690 al 1890 I: 497 y ss. Roma: Filippo Cuggiani; y Nicolini, F. 1942.

25 Fisch, M. H. 1953: 537-541; G. Gimma, 1703: 159-167; Crescimbeni, G. M. 1720: 220-223; Carini, I.; F. Niccolini (ed.) 1905 Pietro Giannone Vita. Nápoles 48: 1905; Quondam, A. 1970. “Dal Barroco all'Arcadia”, in Storia di Napoli: IV, Napoli.

${ }_{26}$ Su proceso fue el más largo de todos, pero después de abjurar y bajo estricta vigilancia pudo volver a su investigación matemática. En 1700 publicó De constructione aequationum libellus, en Nápoles, obra que recibió el elogio de Leibniz en la revista Acta eroditorum Lipsiensium, donde se afirmaba que De Cristoforo había logrado pasar a la combinación y construcción de ecuaciones cúbicas y cuadradas sin seguir el método cartesiano de eliminar el segundo término. Esta obra fue elogiada también por Antonio Magliabechi, Domenico Guglielmini y miembros de la Academia de París. Su obra Della dottrina Del Pezzo (Venecia, 1720), versaba sobre cálculo diferencial aplicado a los
Basilio Giannelli (1662-1716) ${ }^{27}$ y Francesco Paolo Manuzzi. ${ }^{28}$ La Inquisición los acusaba de disertar sobre las doctrinas de los átomos de Epicuro, Lucrecio, y sobre la mortalidad del alma. ${ }^{29}$ Aunque la explicación más difundida sostiene que esta acción fue llevada a cabo por la Inquisición con la intención de "persuadir" a los intelectuales de la época a que evitaran entrar en discusiones concernientes a la fe y la religión en sus investigaciones, ${ }^{30}$ la tesis de que su objetivo era también sacudir a los miembros de la academia, que habían ayudado a popularizar doctrinas consideradas "heréticas", así como las tendencias anticuriales de los juristas, no contradice a la primera. El juicio era una iniciativa para combatir la heterodoxia y reafirmar la posición del Santo Oficio en Nápoles. ${ }^{31}$ El juicio fue interrumpido debido al terremoto del 5 de junio de 1688, que impidió que los acusados fueran arrestados. El arresto de Belli y De Cristofaro tuvo lugar sólo tres años más tarde, después de la elección del Papa Inocencio XII, bajo la acusación de enseñar postulados ateístas y heréticos a través de sus teorías atómicas. ${ }^{32}$

problemas trigonométricos. Se sabe también que de Cristofaro continuó la investigación de Cornelio sobre el flujo de la sangre en el cuerpo; al respecto escribió una carta a Guglielmini en 1701 que fue publicada sólo hasta 1730: Intorno al suo opuscolo sulla natura del sangue, aggiuntavi un'opinione circa il moto del cuore. Cfr. Cappello, C. 1946. G. B. Vico e il processo contro ateisti napoletani, in Salesianum VIII: 328 y ss. De Giovanni, B. 1970. La vita intellettuale a Napoli en Storia di Napoli. VI 1: 432 Nápoles; Comparato, V. I. 1970. G. Valletta: 143-48 Napoli.

27 Gianelli escribía poesía y era parte del movimiento neopetrarquista en reacción al marinismo. Junto con Leonardo Di Capua, Tommaso Cornelio y Carlo Buragna, desarrolló esta corriente en la poesía que condujo a la creación del lenguaje simple y musical de la Arcadia. En 1689 publicó un volumen de Poesie. Fue amigo de Giuseppe Valletta, Gregorio Caloprese, Nicolò Caravita, Antonio Magliabechi y del joven Giovan Battista Vico entre otros. Entre 1681 y 1684 escribió sus primeras líricas amorosas. Después del episodio con la Inquisición, escribió Delle rime scelte di vari illustri poeti napoletani (Firenze, 1723). En 1701 publicó Orazione per l'elezione del gloriosissimo Filippo $V$ in re delle Spagne, a petición de Andrea d'Avalos, príncipe de Montesarchio, quien había guiado ese mismo año la represión de la conjura filo-austriaca conocida como la Conjura de Macchia. En torno a 1710 escribió Educazione al figlio, una colección de consejos y preceptos dedicada a su hijo Domenico, inspirada en la obra de Francesco D'Andrea, Avvertimenti ai nipoti. De forma póstuma apareció, Educazione al figlio dell'avvocato (1781), que es un cuadro sobre las emociones durante los primeros años del siglo XVIII. Cfr. Crescimbeni, G. M. 1721: 136-140; Giannantonio, P. 1962. L'Arcadia napolitana: 142 y ss Nápoles: Liguori; Mastellone, S. 1965. Pensiero politico e vita culturale a Napoli nella seconda metà del Seicento: Florencia: D'Anna; Quomdam, A. 1970. Dal Barroco all'Arcadia, Nápoles 143-148: Società editrice Storia di Napoli.

28 Osbat, L. 1974. L'inquisizione a Napoli. Il processo agli ateisti, 1688-1697, Roma: Edizioni di storia e letteratura.

29 Niccolini, F. 1942: 83.

30 Nuzzo, E. 2012. "Between Orthodoxy and Heterodoxy in Italian Culture in the Early 1700s: Giambattista Vico and Palo Mattia Doria" en Robertson J. y S. Mortimer (eds.) The intellectual consequences of religious heterodoxy: 1600-1750: 206-234, Leiden: Brill.

31 Amabile, L. 1829. II Santo officio della Inquisizione in Napoli: narrazione con molti documenti inediti, Città di Castello: S. Lapi; Minieri Riccio, C. 1879 Cenno storico delle Accademie fiorite nella città di Napoli, en Archivio storico per le province Napolitane IV; Colapietra, R. 1961 Vita pubblica e classi politiche del viceregno napoletano (1656-1734) Roma: Edizioni di Storia e Letteratura; Galasso, G. 1970. "Napoli nel viceregno spagnolo dal 1648 al 1696". Storia di Napoli VI: 169 e Id., 1972. "Napoli nel vice regno spagnolo 1696-1707", Storia di Napoli VII: 185.

32 Osborne, L. 1974. 
De esta forma es que el juicio de los investiganti se convirtió en el de los "atomistas-ateístas" y desató un movimiento que reunió a un número importante de intelectuales napolitanos que empuñaron la pluma en defensa de sus pares. Los más activos escribieron; otros se limitaron a la recolección de alrededor de 6000 firmas a favor de los acusados. Entre los textos más notorios se encuentran los de Francesco D’Andrea, Apologia in difesa degli atomisti; su Risposta a favore del Sig. Lionardo di Capoa $(1697)^{33}$ y el de Niccolò Caravita, Ragione a pro della fedelissima città e Regno di Napoli contr'al procedimento straordinario nelle cause del Sant'Officio (1695) entre muchos otros. ${ }^{34}$ Pese la actividad inicial, los académicos no pudieron soportar la presión de la Iglesia, que pronto los dividió en varios frentes: algunos de los aristócratas se decantaron de lado de la Iglesia, otros se exiliaron y los demás tuvieron que guardar silencio frente a la retractación de los acusados con la que terminó el juicio en $1697 .{ }^{35}$

La opinión de los especialistas al respecto del juicio de los atomistas es controversial, muchos le han negado importancia, considerándolo de poca monta; no obstante, la realidad es que el episodio de los novatori guió la pluma de muchos intelectuales napolitanos durante las siguientes décadas en contra de los miembros de la Compañía de Jesús, a quienes veían como los responsables directos de la cacería emprendida contra los investiganti, me refiero sobre todo a los que tenían la posición social para enfrentar a los jesuitas públicamente. Aun así estos eran conscientes de la fragilidad de la autoridad papal, su ardua búsqueda por restablecerla desde Trento (1563), y temían la represión de la Compañía de Jesús en defensa de la ortodoxia.

Además de haber sido un freno a la libertad para investigar en su momento, este juicio fracturó la cultura napolitana, influyendo también a generaciones sucesivas, ya que este hecho dejó claro que el Papa y los jesuitas habían estigmatizado a todos aquellos relacionados con los investiganti, a los que consideraban los enemigos más peligrosos de la ortodoxia en el reino. En Nápoles la ortodoxia peligraba porque tendía: primero, al distanciamiento de la filosofía escolástica y a la búsqueda de la libertad para filosofar y, segundo, porque el distanciamiento llevaba al surgimiento de todo tipo de experimentos para llenar el vacío dejado por la Escolástica, entre los que se incluían, aunque no exclusivamente, se incluían grupos simpatizantes de los principios jansenistas. La investigación experimental en la ciencia y la filosofía, como había enseñado Galileo, era el

33 Cortese, N. 1923. I ricordi di un avvocato napoletano del Seicento, Francesco D’Andrea. Napoli: L. Lubrano; Borreli, A. 1981. "L'apologia in difesa degli atomisti di F. D’Andrea”. Filologia e Critica VI: 259- 267; véase también Quondam, A. 1979 “Minima Dandrein. Prima ricognizione sul testo delle Risposte di F. D’Andrea a B. Aletino" Rivista storica italiana LXXXII: 887-916.

34 Caravita, N. [1695], 1705. Ragioni a pro della fedelissima città e Regno di Napoli contr'al procedimento straordinario nelle cause de Sant'Officio, divisate in tre capi. Nel I si ragiona del grave pregiudicio della real giuridizione, Nel II si tratta dell'ordinaria maniera di giudicio, che tener si dee nel regno, e nel III si dimostra il pregiudicio, che fa alla real giuridizione, ed al regno un editto in cui si stabilisce il tribunal della 'nquisizione, Napoli.

35 Fisch, M. H. 1953: 549-550. principal problema para la Iglesia porque representaba el vehículo para la propagación de nuevos paradigmas que acababan con el monopolio de la Escolástica. Ahora bien, independientemente de que el juicio contra los ateístas haya frenado la velocidad del desarrollo de nuevos paradigmas filosóficos, lo cierto es que estos eventos de finales del siglo XVII marcaron ciertamente la intención y la forma en la que los intelectuales napolitanos presentaron el resultado de sus investigaciones en ese periodo y en las décadas venideras. $^{36}$

Por lo que respecta al segundo punto señalado al principio de este apartado, al hecho de que las Cartas de Doria puedan ser vistas como réplica al lugar común que sostenía que el jansenismo se había ido afirmando, a partir del surgimiento de la Accademia degli Investiganti, como la tendencia moral y política dominante en el sur de Italia, atribuyéndole un lugar central en los fundamentos de la Ilustración napolitana, ${ }^{37}$ el hecho de que este texto haya sido escrito precisamente alrededor de 1731, nos permite saber con más precisión que el auge de las teorías jansenistas en Italia no tuvo lugar paralelamente, a la articulación de la crítica a los jesuitas, la cual fue in crescendo hasta alcanzar su punto más alto a finales del siglo XVIII. Por otra parte, nos permiten entender los puntos sobre los que versó la crítica a los jesuitas, lo que a su vez nos sirve para evaluar si los jansenistas podían sustituirlos en algún momento. En conjunto todos estos elementos nos ayudaran a ubicar con más precisión el momento en que la filosofía jansenista se hace popular en el napolitano, lo que tiene que haber ocurrido después de la redacción de este manuscrito. ${ }^{38}$ Por otra parte, este hallazgo nos permite constatar que la articulación del binomio jansenismo-cartesianismo había sido acuñado en el contexto de la academia florentina del Cimento y que para los napolitanos los jansenistas no estaban en grado de llenar el vacío que la Escolástica estaba dejando desde el punto científico, moral y político precisamente porque los jansenistas se encontraban entre los principales antagonistas del Papa. Según el filósofo genovés radicado en Nápoles todos conocían bien la forma en la que había sido utilizada la obra de Nicole (1625-1695), esto es, para ayudar a fortalecer la autoridad de los príncipes seculares y sabían también que éste texto no podía ser usado en sentido contrario para defender la autoridad papal. Por lo tanto, todo parece indicar que los napolitanos sabían que los jansenistas no podían sustituir a los miembros de la Compañía de Jesús

36 Lo que sí es seguro es que aún en 1730 la acción de la censura era extramademente activa. Prueba de ello fueron el debate sobre Spinozismo en Nápoles entre Doria y Francesco-Maria Spinelli y el temor que manifiesta el mismo Celestino Galiani de que se sepan los senderos intelectuales que recorrieron a finales del siglo XVII junto con Gregorio Caloprese; además, en la década de 1750, fue condenada y quemada inmediatemante después de su publicación la obra de Doria, Idea d'una perfetta repubblica (Nápoles, 1753).

37 Capone, Braga G. 1920. II: 6; Jemolo, A. C. 1928; Stella, P. 1966: I-II.

38 De Giovanni, G. M. 1954. "Il Giansenismo a Napoli nel secolo 18", Asprenas. Napoli; Aquarone, A. 1962. "Giansenismo italiano e rivoluzione francese prima del triennio giacobino" Rassegna storica del Risorgimento: octubre-diciembre 560-624. Rosa M. 2014. Il giansenismo nell'Italia del Settecento: dalla riforma della Chiesa alla democrazia rivoluzionaria. Roma: Carocci. 
en dos de sus funciones principales a saber, como protectores de la autoridad del Papa, así como tampoco podrían poner a salvo la ortodoxia católica, porque ellos habían sido un elemento desestabilizador importante en la era de la Contrarreforma. Por esta razón, cuando las obras de los jansenistas fueron distribuidas en Nápoles por miembros de la curia, como fue el caso de la obra de Arnauld, se hizo con el fin de atacar la moral relajada de la Compañía de Jesús, sin embargo, no se pensaba que éstos pudieran sustituirlos en su función primordial, al menos no a finales del siglo XVII, así como tampoco hasta la década de los treinta, cuando Doria escribió esta obra. ${ }^{39}$ Esta información no descarta la posibilidad de que haya habido grupos de jansenistas en Nápoles en la época, pero sí que la difusión de su obra la hayan hecho los cartesianos miembros de la accademia degli investiganti, como se había presumido inicialmente. Por otra parte, Doria hace referencia a la enorme necesidad de llenar el vacío dejado por la filosofía Escolástica y las dificultades que tuvieron que enfrentar los filósofos de su tiempo para encontrar un nuevo fundamento científico, moral y político para la vida civil. El grado de consciencia de dicho vacío dejado por la Escolástica pudo haber sido el elemento que incentivó la alta productividad de los investiganti registrada hacia finales del siglo XVII.

\section{LA LABOR DE DORIA EN LA BÚSQUEDA DEL NUEVO PARADIGMA FILOSÓFICO.}

La posición de Doria en esta cuestión tiene que ser analizada en dos niveles: tomando en cuenta por un lado, lo que él explícitamente comunica al lector, y por otro, lo que realmente hace con su filosofía política en conjunto. Aquí nos interesa especialmente el segundo nivel. La crítica de Doria a los jesuitas no inicia con estas Cartas escritas alrededor de 1731. La distancia del filósofo genovés respecto de los miembros de la Compañía de Jesús es notoria ya de alguna manera en la obra que le valió el reconocimiento de los miembros de la Respublica literaria: La Vita Civile (1709). ${ }^{40}$ Acorde con el descontento de los hombres de letras y de los círculos intelectuales que Doria frecuentaba a comienzos del siglo XVIII, esta obra no es favorable a la Escolástica. ${ }^{41}$ La crítica tampoco es abierta ahí, posiblemente debido a que aún era reciente el incidente de los atomistas y la censura era muy activa, pero también puede ser que Doria no tenía del todo claro iniciar un ataque directo contra los miembros de la Compañía de Jesús. Sin embargo, el distanciamiento de concepciones aristotélico-tomistas son ya claras en este momento y se van haciendo más notorias a lo largo de su vida intelectual, como puede verse en sus textos Discorsi critici-filosofici intorno la filosofia degli antichi e dei moderni,

\section{Doria, P. M. 1731: 334.}

40 Doria, P. M. 1710. La Vita Civile di Paolo Mattia Doria distinta in tre parti, aggiuntovi un trattato della Educazione del principe, Seconda edizione dall'autore ricorretta, ed accresciuta 434. In Augusta, appresso Daniello Hopper.

41 Luna González, A. 2009. From Self-love to Self-liking in Paolo Mattia Doria: Civil Philosophy and Natural Jurisprudence in the Early Italian Enlightenment, tesis doctoral, Florencia: European University Institute. publicado en $1724,{ }^{42}$ y en su Filosofia de $1728,{ }^{43}$ hasta llegar a una serie de escritos inéditos de las últimas décadas de su vida, a saber, Lettere al Reverendissimo Padre Generale de 1731, II Gesuita Tirano de 1737,44 II Politico alla Moda de 1739 y la Lettera Terza nella quale prima si mostra, che i Pagani sono stati più esatti osservatori delle umane virtù, che noi Cristiani de 1739, hasta su muerte, que acaece en $1746 .{ }^{45}$ Paralelamente al distanciamiento de los principios escolásticos, a partir de la década de los veinte, comienza a hacerse visible también su distanciamiento de los modernos, lo cual lo coloca en una posición ambigua. Para este artículo hemos tomado Le Lettere de 1731 como punto de referencia porque es el documento donde Doria asume la crítica a los jesuitas de forma sistemática; además, es ahí donde elabora un examen extenso a los problemas de la casuística como método para impartir justicia, del cual se desprende su complejo análisis sobre la filosofía, lógica, teología, la forma de enseñanza ejercida por la Compañía de Jesús, la forma de predicar de sus miembros en China, y retoma finalmente sus costumbres y la forma en que llevan a cabo la confesión. Por razones de espacio, este artículo se enfoca principalmente en el método, la filosofía, la lógica y la teología.

El texto que conforma Le Lettere está articulado en siete cartas dirigidas al padre General de la Compañía de Jesús. Éstas tienen forma de diálogos temáticos en los que participan cuatro personajes: un escrupuloso penitente de los jesuitas, un contrario a ellos, un discípulo de su escuela (éste representa la opinión de Doria), y un joven cartesiano. Los dos primeros llevan el debate que es matizado de cuando en cuando por el joven jansenista y en el que el discípulo de la escuela, interviene sólo al final de la obra. Sobre la forma llaman la atención dos elementos: uno, que en el diálogo Doria se coloque ficticiamente como discípulo de la escuela y dos, que haya elegido esta forma de diálogo y el título, ya que Doria sabía que lo asociarían con las Lettres Provinciales de Pascal. Doria sabía que lo considerarían un imitador de él o, que por lo menos, lo reputarían opositor de los jesuitas como los autores de Port Royal. Esto es, al elegir estos elementos quería crear ambigüedad. Advierte, además, a sus lectores que era posible que sus contemporáneos argumentaran que la intención detrás de estas Cartas

42 Doria, P. M. 1724. Discorsi critici-filosofici intorno la filosofia degli antichi e dei moderni ed in particolare intorno la filosofia di Renato Des Cartes, Con un progetto di una Metafisica di P.M. Doria, Venezia [but Naples].

43 Especialmente Doria, P.M. 1728. La Filosofia di Paolo Mattia Doria, con la quale si schiarisce quella di Platone, Dedicata all'Altezza Reale di Carlo Emanuele Principe di Piemonte I: IV Amsterdam [Ginebra]: Tournes.

44 Doria, P.M. [1737] 1982. "II Gesuita Tirano: Lettera II. Ad un'Amico Divisa in Capitoli Nella quale dop. essersi narrate l'Eresie, delle quali i Gesuiti sono stati accusati, si discopre una perniciossima Setta, ch'essi propagano nel Mondo in Materia di Morale; Con l'aggiunta di alcune Lettere dall'Autore indirizzate al Padre Generale della Compagnia di Ges.. Dedicata alla Serenissima Repubblica di Lucca”, en Belgioioso, G. (ed). I: 401-473.

45 Doria, P.M. 1982 "Lettera Terza Nella quale prima si mostra, che i Pagani sono stati più esatti osservatori delle umane Virtù, che noi Cristiani; e poscia s'indaga la cagione di questo a noi vergognoso effetto', en G. Belgioioso III: 245-277. 
era la venganza, debido a la discrepancia del autor con los padres del Colegio de Génova, su patria, quienes lo llevaron a perder una gran suma de dinero, sobre la que los jesuitas alegaron "no tener interés", pero que recibieron igualmente. ${ }^{46}$ Este hecho fue muy conocido en la época ya que involucró a jueces y abogados a los que Doria acusó más tarde de "secuestrar violentamente su propiedad", y a quienes llamó "jesuitas bandidos de caminos". ${ }^{47}$ Doria previene que muchos lo descalificarían a causa de estos eventos y argumentarían que él atribuía a toda la Compañía, juicios a partir de hechos aislados, o que tenía una visión sesgada por el juicio contra él. Sin embargo, esperaba que al escuchar la verdad de los hechos, los lectores confiarían en él, que su crítica pasaría a la posteridad y que todos podrían ver el carácter nocivo de los miembros de la Compañía, que en su opinión, eran "una plaga que extendía sus raíces a todo el cuerpo", de la sociedad. ${ }^{48}$

Desde el inicio, Doria aclara que la crítica que hace a los jesuitas se refiere a temas terrenales y que por ningún motivo debe ser vista como ofensa a la veneración que se debe a su carácter sacrosanto como sacerdotes. En ese sentido, debemos compadecernos de los vicios de debilidad que puedan tener los que están sujetos, como todos los hombres, a los vicios que ofenden a la república. Pero aclara que no por esa adhesión estamos obligados a simpatizar con los vicios de iniquidad como el robo y la calumnia, ni estamos obligados a tolerar las fallas en otras personas, salvo en el caso de superiores, como el vicario de Cristo y los príncipes, que, siendo instruidos por Dios, los hombres no pueden juzgar. ${ }^{49}$ Contra todos los otros ordenes de personas podemos expresar nuestras razones cuando éstas nos hayan ofendido u opreso. ${ }^{50}$ Con ironía, enfatiza que las congregaciones religiosas no pueden pretender la misma inmunidad de los príncipes, pues los hombres no tienen por qué sufrir su tiranía, ya que precisamente sus miembros impíos habían escrito que era lícito que los vasallos asesinaran al tirano en causa justa. ${ }^{51}$

Este deslinde al comienzo de la obra es crucial porque a pesar de que el documento ha sido escrito en la década de los treinta y de que sus obras han pasado la censura de la Inquisición en Nápoles en repetidas ocasiones, nos indica que el filósofo genovés teme levantar sospechas. A Doria le preocupa que su obra y su persona sean vinculados con los modernos, con los ateístas-atomistas cartesianos, con quienes ha departido en varias academias donde concurrían, o bien miembros originarios o descendientes de la Accademia degli Investiganti, como en el caso de la tertulia en casa de su amigo Niccolò Caravita a finales del siglo XVII, o la Palatina

\footnotetext{
46 Doria, P.M. 1731: 231-9.

47 Doria, P.M. 1731: 232.

48 Doria, P.M. 1731: 234.

49 Doria sostiene la opinión opuesta en la Vita Civile de 1709. Cfr. Doria, P.M. 1710.

50 Doria, P. M. 1731: 234

51 “... ma invero niuno meno, che i Gesuiti ci protrebbe costringere a soffrire la Tirannia della loro Società, impercioche avendo i loro Autori di Morale empiamente scritto esser lecito al Vassallo di uccidere il Tiranno, non potrebbero poi, senza incorrere nel delitto di sfacciataggine dire, che noi dobbiamo tolerare la Tirannide delle Società Religiose." Doria, P. M. 1731: 235
}

Accademia de Medinacoeli, que no sólo frecuentó durante su existencia (1698-1702), sino que fue príncipe director en algún periodo. Si bien es cierto que han pasado tres décadas, no deja de llamar la atención el hecho de que Doria sigue interesado en tomar distancia de los modernos. En las Cartas no menciona a los atomistas napolitanos y su juicio, ni tampoco lo hace en algún otro texto, esto es, presenta su crítica a los jesuitas pero no los ataca a través de los temas más delicados de la época. Pero ahí por primera vez en su obra asocia cartesianismo, atomismo, jansenismo y filosofía moderna, pero lo hace en relación con la florentina Accademia del Cimento (1657-1666). ${ }^{52}$

En sus Cartas, Doria se deslinda de los modernos, pero no los ataca, y puede que lo haga así para indicar a sus lectores que su obra está libre de heterodoxia, entendida en la ecuación antes mencionada para la academia del Cimento. ${ }^{53}$ Por la forma como procede parece que su objetivo era en realidad proponer que su filosofía ocupase el vacío filosófico que él mismo denuncia en este texto de 1731. Al respecto hay un punto que merece la pena destacar, en algún momento, el filósofo genovés explica al General de la Compañía o a su posible censor que ha seguido algo así como "los requerimientos para publicar en el Nápoles de su tiempo". En un pasaje expone que en su Filosofía, publicada en 1728 , a pesar de que él es un seguidor de Platón, ha alabado la filosofía de Aristóteles y se ha opuesto abiertamente a la filosofía de los modernos, adversarios de los jesuitas. Ahí mismo menciona que lo ha hecho para evitar la censura. A este punto es cuando parece estar negociando abiertamente la aceptación del texto del que ahora nos ocupamos. ${ }^{54} \mathrm{Y}$ lo hace afirmando que no entrará en materia de fe y que no pondrá en jaque la ortodoxia, tan importante a lo largo de todo este periodo. Doria explica que la crítica a los jesuitas que verán en sus Cartas no tocará ninguna máxima de la Iglesia, a la que falsamente ellos dicen defender, así como tampoco vuelve al tema de los investiganti. Declara que quiere mostrar que los jesuitas son para la Iglesia como las milicias auxiliares mercenarias y mal disciplinadas en el arte de la guerra, que son usadas por los príncipes en las batallas y que al final terminan buscando sus ventajas privadas y se olvidan de los fines para los que fueron contratados. ${ }^{55}$ Prosigue argumentando que su texto dará los elementos necesarios para probar su crítica de forma tal

52 Sobre este vínculo en Nápoles cfr. Garin E. Storia della filosofia italiana: 889-99 y 917-918 Torino: Einaudi y Zambelli, P. 1972. La formazione filosofica di Antonio Genovesi. Nápoles: Morano.

53 "... e dico, che nella mia Filosofia, ed in tutte le altre mie Opere io hò bensì contradetto a i loro contrarj [dei i gesuiti], che sono i Filosofi seguaci di Renato Des Cartes, ed i Giansenisti, ma che non hò mai approvato la loro Filosofia, e neppure la loro Morale..." Doria, P. M. 1731: 236- 237.

54 "In ciò che riguarda poi la Filosofia, abbenche io sia in tutto parziale di quella di Platone, hò sommamente lodato la Filosofia delle Scuole, e mi sono contentato di opponermi ai Moderni Filosofi Vostri Contrarj, senza niente giudicare intorno alla vostra Filosofia." Doria, P.M. 1731: 241.

55 "... che i Gesuiti hanno fatto con Santa Chiesa quello appunto, che fanno quelle Milizie Ausiliarie, e Mercenarie, e mal disciplinarte nell'Arte della Guerra, le quali impegnano i Prencipi nelle guerre senza avere valore per difendergli, e poscia lasciandogli nelle piste, procurano solamente i loro particolari vantaggi;..." Doria, P.M. 1731: 238. 
que los devotos de la Compañía de Jesús no lo consideren ni injusto ni apasionado. Pero también podríamos agregar que Doria tal vez quería que los jesuitas lo vieran como un posible candidato para contribuir a su labor.

\section{LA FILOSOFÍA DE LOS JESUITAS}

Una de las partes más interesantes de las Cartas es la referente a la filosofía de los jesuitas, en particular a los fundamentos de la Escolástica. Los tintes que toman el debate y la llamativa explicación del penitente de los jesuitas merecen su reproducción, aunque sea parcialmente. Según él, los miembros de la Compañía de Jesús no fueron los inventores de la Escolástica, sino que ésta fue obra de Aristóteles. En su explicación, esta filosofía pasó a los árabes que la enseñaron en España, de ahí fue transmitida a París, donde Tomás de Aquinas, considerándola útil para convencer a algunos heréticos, se valió de ella, y fue a partir de entonces que todas las escuelas religiosas la cultivaron extensivamente.

Esta explicación del penitente fue interrumpida por el contrario de los jesuitas para agregar que, "se sabe también que por orden del Parlamento francés fueron quemados en París los escritos de Aristóteles, arguyendo que de ellos se extraía el ateísmo". El penitente de los jesuitas, retomó su relato afirmando que "en realidad los miembros de la Compañía habían modificado de tal forma la filosofía de Aristóteles que a ese punto nadie estaba muy seguro ya que la Escolástica fuera aristotélica”. "¡Por fortuna -interrumpió el joven jansenista - en la actualidad Descartes ha dado un poco de luz a la verdad con su filosofía! De otra forma, los hombres estaríamos sepultados en las tinieblas de la ignorancia en la que nos ha sumido la Escolástica." ${ }^{\prime 56}$ Ante esto, el contrario de los jesuitas respondió que: "Descartes había tratado de contrarrestar a Aristóteles con una filosofía tan vana y perniciosa como la Escolástica". ${ }^{57}$

Retomando el argumento, el contrario de los jesuitas afirmó que: "la filosofía Escolástica era en realidad un escepticismo paliado, sostenido por la sofística, ya que la primera, al mismo tiempo que investigaba la verdad, enseñaba tanto a probar la proposición afirmativa como la contraria, lo que demostraba que no había una verdad. Para esta filosofía era verídico todo aquello que uno lograba probar con un ingenio mejor que el de los demás; por esta razón, no se podía confiar en su criterio para encontrar la verdad, que es una sola. Se sabía - de acuerdo con el contrario de los jesuitasque los círculos de los escolásticos no eran otra cosa que una arenga de la cual salía victorioso el que sabía meter en saco a sus contrarios, haciéndoles confesar lo que los otros quieren, que no era necesariamente la verdad". ${ }^{8}$ "Además

56 La oscuridad de la Escolástica fue también comentada en las Cartas por el contrario de los jesuitas en varias ocasiones cfr. Doria, P.M. 1731: 337.

57 Doria, P.M. 1731: 327.

58 "La Filosofia delle Scuole è uno Scetticismo palliato sostenuto dalla Sofistica; impercioche nelle Scuole nello stesso tempo che si fà professione della recerca del vero, s'insegna a pruovare ugualmente la proposizione affirmativa, e la contraria a quella, ciò che vale a dire, s'insegna, che non v'è alcuna Verità: e che vero ... ed in vero i Scolastic ne' loro circoli altro non fanno, che un'arringo, nel quale quello rimane -añadió- en esos ambientes los disputantes muchas veces no entienden ni siquiera los temas que debaten porque no tienen ninguna idea sobre ellos". ${ }^{59}$

A este punto, el contrario de los jesuitas preguntó a los demás participantes “¿qué es el escepticismo?”. A lo que el penitente respondió, "los escépticos fueron una secta que dudaba de todas las cosas y no asentaban ninguna proposición como verdadera". "Entonces, la filosofía escolástica es un escepticismo, porque no se puede asentar nada como verdadero" - afirmó el contrario de los jesuitas-. "Agregó que también era un escepticismo en virtud de sus términos oscuros y ambiguos y de las definiciones oscuras y confusas, puesto que cada uno puede igualmente sostener la proposición afirmativa y la negativa. Luego, era paliado porque en lugar de decir, como decían los escépticos, que ellos no sabían nada, los escolásticos se vanagloriaban de saber lo que no sabían. Se afirmaba que estaba sostenida por la sofística, porque en su lógica los escolásticos ponían como base de sus silogismos las hipótesis que preferían, de donde después deducían las consecuencias que querían y no necesariamente aquellas que conducían al descubrimiento de la verdad." "Esta filosofía - continuó el contrario de los jesuitas- es la que ha abierto el campo para asentar en la moral aquellas proposiciones perniciosas e inauditas con las que los jesuitas han estropeado y corrompido la justicia, argumentando cualquier cantidad de hipótesis falsas a placer" ${ }^{60}$

"Esta filosofía no ha corrompido por sí sola la justicia de los tribunales y la moral de la república" - sentenció el contrario de los jesuitas. "La verdad, era que todas las impertinentes sentencias de moral de los jesuitas se derivan, según Ricci, de la lógica que enseñan". El penitente interrumpió diciendo que: "esa misma lógica la enseñaban los dominicanos en sus escuelas y, por otra parte, además de la filosofía de los modernos, no había otra a la cual recurrir."61

Ante esto, el contrario de los jesuitas argumentó que: "el abuso de la lógica fue lo que causó el problema de los tribunales, pues los jesuitas creyeron que con sus falsos modos y usando términos de Aristóteles probarían, tanto en moral como en teología, todas las proposiciones extrañas que quisieran y que serían útiles a sus fines: complacer las conciencias y corromper la justicia. Así, movidos por su afán de enriquecerse, los jesuitas habían formado una filosofía, una teología y una moral licenciosas, alejándose

Vittorioso, che hà saputo com'essi dicono porre in Sacco il loro Contrario facendogli confessar quel che vuole, non quel ch'è vero. Doria, P.M. 1731: 319 y 328.

59 Doria, P.M. 1731: 337.

60 "... gli Scettici furono di quella Setta, che dubitava in ogni cosa, e non assentava alcuna proposizione per vera. II Vostro Contrario: se nella filosofia scolastica non si può assentar niente di vero, ella è uno Scetticismo. Ed in vero altra cosa non è la Filosofia delle Scuole, che uno Scetticismo, e ciò perche in Virtù delli termini oscuri, ed ambigui, e delle definizioni oscure e confuse ogn'uno può assentare qual proposizione gli piace d'assentare, e ciascheduno può ugualmente sostenere la proposizione afirmativa, e la negativa; ... Questo lor palliato Scetticismo poi è sostenuto dalla Sofistica, perche nella loro Logica essi hanno per costume di ponere per base de' loro Sillogismi quelle Ipotesi, che loro più piacciono, onde poi ne deducono quelle conseguenze, che vogliono, non quelle, che conducono allo scoprimento del Vero..." Doria, P.M. 1731: 338.

61 Doria, P.M. 1731: 328. 
completamente de los textos originarios. Esto no fue hecho por los dominicanos, quienes siempre se mantuvieron firmes en la filosofía aristotélica y en la doctrina de Aquinas". A esto se debía agregar -irrumpió el contrario a los jesuitas- que "los dominicanos no tuvieron como lo jesuitas un Luis de Molina (1535-1600), así como tampoco, más de cincuenta autores condenados por la Universidad de París, muchos incluso por el mismo Papa durante el siglo anterior". "Al final, esta Compañía que nació en el siglo XVı había creado un ejército de falsos teólogos y moralistas contra la religión y la justicia al inicio del siglo XVII." ${ }^{62}$

Ante estas afirmaciones, el penitente de los jesuitas respondió que "los autores condenados por la Universidad de París y el clero de Francia fueron precisamente aquellos jesuitas que sirvieron de escudo a la santa Iglesia. Con su filosofía y su teología Escolástica, habían sido el martillo contra los insultos de los jansenistas, cartesianos e incluso contra los heréticos; por tanto, se hacía mal en considerarlos malos y licenciosos. Con ellas, también explicaron cosas contra los luteranos y filósofos cartesianos que ni éstos habían sido capaces de abordar. De todos estos debates contemporáneos, -agregó el penitente- puede considerarse que los jesuitas han salido triunfantes." ${ }^{63}$

La victoria de los jesuitas en el plano filosófico fue puesta en duda por casi todos los participantes del debate. El contrario recordó algunos casos relacionados con cuestiones teológicas en los cuales los jesuitas salieron triunfantes como aquellas contra calvinistas y luteranos, y muchos otros más. Entre los miembros respetables de la Compañía de Jesús, recordó al cardenal Belarmino, al cardenal Sforza Pallavicino y, sobre todo, al monseñor Bossuet (1627-1704), arzobispo de Meaux, que con su excelente libro sobre la Historia de las variaciones y el resto de sus obras convenció a los heréticos de sus errores. ${ }^{64}$ Sin embargo, recordó que nadie había logrado convencer a los jansenistas en Francia. "No sólo nadie los había persuadido, sino que además ellos habían llegado a un punto muy similar al de los heréticos, luteranos y calvinistas. Luego de la condena del Papa a las proposiciones de Cornelio Jansenio (1585-1638), sus seguidores y amigos, el abate S. Cirano, Antoine Arnauld (1612-1695), hermano de la madre Angélique Arnauld (1591- 1661), Sacy, Andilly, y muchos otros contrarios a las proposiciones de Molina, tomaron la disputa sobre las proposiciones afirmando que éstas no se encontraban en el libro Augustinus (1640) de Jansenio. Este hecho en realidad estas proposiciones marcaron el inicio de otra disputa en Francia, esta vez sobre la infalibilidad del Papa en materia de hecho. Como se sabía, las religiosas de Port Royal, aconsejadas por Arnauld, se negaron a firmar el formulario en la parte que concierne la intervención del Papa en materia de hecho. Posteriormente, fueron exhortadas nuevamente a hacerlo hasta que finalmente fueron condenadas por el arzobispo de París. Bien mirado -afirmó el contrario de los jesuitas- este incidente fue uno de los fracasos más grandes

62 Doria, P.M. 1731: 329-30.

63 Ibidem.

64 Doria se refiere a Histoire des variations des Églises protestants (1688). Doria, P. M. 1731: 331 y ss. de los jesuitas, ya que llevó a la Iglesia a decretar que todos los católicos debían acatar los hechos revelados sobre los cuales se decidió el caso y, sobre todo, puso en riesgo la infalibilidad del Papa. ${ }^{65}$ La Compañía de Jesús tuvo que tratar como heréticas a las religiosas de Port Royal desatando la reacción de sus simpatizantes y de los católicos. El mismo Pascal denunció en sus Cartas Provinciales la moral de los jesuitas, quienes se creían los vencedores de la disputa y de los tumultos suscitados en los curatos en Francia, solicitando la prohibición de las proposiciones impías. Por otra parte, -añadió el contrario- recuérdese en ese mismo espíritu victorioso de los jesuitas, al padre Amadeo Guimenio (1610-1684), quien escribió el libro en el que glosaba varias proposiciones y que le valieron la condena de la Universidad de París; ${ }^{66}$ a pesar de que el mismo Papa no estuviera de acuerdo con ella. No porque aprobase el libro, sino porque no le parecía que la Universidad se tomara sendas facultades de prohibir libros a título propio. Así, los jesuitas no sólo mantuvieron abierta la disputa con los jansenistas, sino que la fomentaron hasta la llegada de Pasquier Quesnel (1634-1719) y la publicación de sus 108 proposiciones en las que sostenía, como lo había hecho Jansenio, la doctrina de la gracia. ${ }^{67}$ Fue finalmente este hecho el que llevó al Papa Clemente XI a proclamar la bula Unigenitus en 1713 para condenar la herejía de Jansenio y 101 de las proposiciones de Quesnel." 68

El debate lo continuó el contrario de los jesuitas añadiendo que: "en realidad a partir del momento en que los jesuitas se ocuparon de la defensa de la Iglesia las cosas empeoraron como nunca antes, como puede apreciarse en el caso de los calvinistas y los luteranos que no sólo se separaron de la religión sino también del Estado. Recordó que, ya antes del Concilio de Trento y del surgimiento de la Compañía de Jesús, habían surgido varias sectas como la de los Arianos, que desaparecieron del todo sin mayor problema. Pero hasta ese entonces, las cosas no eran como parecían, pues a pesar de que el jansenismo parecía extinto en Francia, gracias al celo del cardenal de Fleury, todos sabían que el fuego ardía bajo las cenizas." Para concluir su intervención, sostuvo que no veía ningún efecto positivo en el establecimiento de la Compañía de Jesús. ${ }^{69}$

Entonces, el penitente disintió: "si bien es cierto que la Compañía había sido muy ardiente contra los enemigos de la Iglesia, siempre había sostenido con vigor su autoridad y jurisdicción." A este punto el contrario de los jesuitas contra argumentó que: "ellos habían dañado infinitamente a la Iglesia precisamente porque la lucha por fortalecer la

65 Doria, P. M. 1731: 332.

66 Doria se refiere a Mateo de Moya cuyo seudonimo era Amadeo Guimenio, Lomarensi. Ca. 1662. Adversus quorumdam expostulationes contra nonnullas iesvitarum opiniones morales, Valentiae: Typis Bernardi Nogues.

67 Como se sabe las Réflexiones morales sur le Nouveau Testament de Quesnel fueron tan importantes para el jansenismo como lo fue el Augustinus de Jansenio. En español se le conoce a este texto como el Nuevo testamento de Quesnecio. Se sabe de la circulación de este texto desde 1668, sin embargo, la primera versión publicada data de 1692.

68 Doria, P. M. 1731: 333. Esta bula representa el final de la toleracia Católica a la doctrina Jansenista.

69 Doria, P. M. 1731: 26. 
autoridad del Papa contra los jansenistas era lo que los había llevado a perder autoridad, y no sólo con los partidarios de los jansenistas, sino también, con todos los contrarios a la filosofía Escolástica. Todos los hombres de letras seculares, viéndose tratados como heréticos por los jesuitas, se reunieron del lado de los príncipes seculares contra la autoridad de la Iglesia y contra la jurisdicción temporal del Papa. Exhortaba por ejemplo, a mirar la moral de Nicole para ver que, al mismo tiempo que predicaba una moral conforme a las máximas rigurosas de los jansenistas, reforzaba la autoridad de los príncipes, los adulaba de la misma manera en que los jesuitas habían adulado a los papas. Como éste, -decíaeran innumerables los libros de los seculares en contra de la autoridad de Roma y de la jurisdicción eclesiástica, a pesar de las acciones emprendidas por la Compañía de Jesús." Para el contrario, no era cierto tampoco que esos libros no dañaron a Roma y los jesuitas, puesto que en ese entonces se les veía y contaban poco o nada en las cortes europeas. ${ }^{70}$

El penitente de los jesuitas respondió que: "dudaba que a la decadencia de la autoridad de Roma hubieran contribuido exclusivamente los jesuitas; más bien creía que ella había hecho su parte para obtener la poca consideración que en ese momento se le tenía." Interrumpiendo, el contrario a la Compañía aseguró que: "al final, el mejor modo de sostener el decoro y la autoridad de la Iglesia no sería a través de sustituirle los enemigos sin tener conocimiento y virtud para convencerlos del error, como han hecho los jesuitas, sino manteniendo el imperio del conocimiento verdadero y sustentando la justicia, porque a largo andar el que más sabe manda a aquéllos que menos saben y todos los hombres se rinden a la justicia. De esta manera, los padres jesuitas no pudieron sostener a la Iglesia con sus declamaciones retóricas, ya que sus contrincantes probaron ser más doctos que ellos."71

"En el campo de la ciencia ya sabemos cómo han ocurrido las cosas - afirmó el contrario de los jesuitas: la historia de la filosofía moderna se parece mucho a la costumbre de la Escolástica de pasar al exceso opuesto de aquello que sostiene el contrario". Acaso por esa razón -añadió- los estudiosos se aferraron a la filosofía experimental en la que tomaban por principio de sus discursos esas pequeñas partes insensibles, o sea, los átomos de la filosofía de Epicuro, por lo que los llamaban atomistas y sensistas. ${ }^{72}$ Así nació, dijo, la Accademia del Cimento en Toscana, en la cual tuvieron lugar los experimentos de Torricelli en torno al vacío y muchas otras bellezas de la física; allí, las experiencias eran demostradas con pruebas deducidas de la Geometría. EI penitente de los jesuitas preguntó: “¿qué hicieron los jesuitas contra esta nueva escuela de Epicuro?" El contrario respondió: "los convirtieron en ateístas, los acusaron ante la Iglesia pero, como ocurrió con los jansenistas de París, no supieron convencerlos; de esta manera, los jesuitas no

70 "Sono innumerabili poi i libri dei Secolari scritti contro l'autorità di Roma, e contro la giurisdizione Ecclesiastica, e tutto cò i Secolari han fatto ad onta de' Gesuiti, che han creduto, che fussero protetti da Santa Chiesa; nè è già, che questi libri dei Secolari non abbiano Molto a Roma nociuto, perche veggiamo, che oggidì nelle Corti poco, o niun conto più si tiene della Corte di Roma." Doria, P.M. 1731: 334.

71 Doria, P. M. 1731: 335.

72 Doria se refiere a los empiricistas. pudieron refutarlos porque los epicureístas confirmaban sus experimentos con pruebas geométricas que los jesuitas no entendían. De la misma forma, los epicureístas pedían demostraciones geométricas de lo que afirmaban los escolásticos, pero los jesuitas no pudieron proveerlas."73 "¿Y cómo los hubieran podido convencer? - preguntó el penitente de los jesuitas." A esto, el contrario contestó: "mostrándoles que la verdad está en las verdades abstractas y eternas y no en las experiencias sensibles como ellos pensaban; también hubieran podido enseñarles que las pruebas geométricas que se hacían en torno a las experiencias físicas no podían servir como demostraciones de los primeros principios de las cosas, donde los fundamentos de los epicureístas eran falsos, a pesar de que sus experiencias hayan sido verdaderas respecto de nuestros sentidos. Sin embargo, los jesuitas nunca hubieran podido convencer a los epicureístas porque, ignorando la geometría, no podían conocer en qué consistía la falsedad de sus demostraciones. Por otra parte, éstos impugnaban con la geometría las proposiciones oscuras, abstractas y confusas de los escolásticos. Frente a esto, los jesuitas no hicieron otra cosa que llamarlos ateos."74

El joven jansenista tomó la palabra para afirmar que esto es precisamente lo que había hecho Descartes con su Metafísica y sus ideas claras y distintas: "convencer a los epicúreos y escolásticos." ${ }^{75}$ El contrario de los jesuitas respondió al jansenista que: "era cierto que Descartes había presentado al mundo su buen gusto en el arte de razonar sobre las verdades eternas con método geométrico, sin embargo, él mismo no había sabido seguir ese método en relación con los eventos particulares. Esto se debía a que en sus meditaciones no había demostrado los atributos del espíritu y de la materia. Por lo que respecta a la física, Descartes había dado pie a las hipótesis, aunque sin demostrar la esencia de las cosas que ponía como fundamento de sus discursos y, por lo tanto, había dado lugar para que los escépticos y los epicúreos elaboraran proposiciones al infinito. Descartes no había demarcado el límite de las ideas claras y distintas que puso como normas de las verdades. Como prueba de ello, añadió el contrario a la Compañía de Jesús, se debía recordar que en sus pruebas de metafísica había pretendido demostrar la distinción entre espíritu y materia sin haber demostrado la existencia de la materia; por lo tanto, concluyó, del sistema de Descartes se desprendió más tarde aquel impío de Spinoza." El joven jansenista se apresuró a responder: "usted afirma esto, pero no podrá probar jamás que Descartes no demostró la distinción en la sexta meditación". En este momento,

73 “... i Scolari si appigliarono all'ecceso opposto, ed abbracciarono la Filosofia esperimentale, e perche prendevan per principj de loro discorsi le particelle insensibili, o siano gli atomi, abbracciarono la Filosofia d'Epicuro, onde poi furono nomati Atomisti, e Sensisti; quindi nacque l'Accademia del Cimento in Toscana, dalla quale ne uscirono l'esperienze del Torricelli intorno al Vacua, e molt'altre belle esperienze intorno alla Fisica; e perche le dimostravano con pruove, che deducevano dalla Geometria, in ciò però che reguarda la parte pratica, e Sensibile, il Mondo da quelle esperienze si lasciava allettare. E quì disse il Vostro Penitente; che federo i Gesuiti contro questa nuova Scuola d'Epicuro? Ed il Controrio: gli mordeveno chiamandoli Ateisti, gli accusavano a Santa Chiesa, ma non gli sapevano convincere..." Doria, P. M. 1731: 340.

${ }_{74}$ Ibídem. 
el contrario de los jesuitas intervino para aseverar que "si bien Descartes había probado su demostración para los que entendían de algebra, no fue así para aquéllos que creían que la verdad era reducible a uno."

"¿Qué hicieron los seculares y los jesuitas con la filosofía de Descartes? - preguntó el joven jansenista." El contrario respondió: "trataron a los cartesianos como a los ateos y los acusaron ante a la Iglesia, aunque nunca pudieron convencerlos porque Descartes en sus meditaciones procede con un método aparentemente geométrico y los jesuitas no lo entendían. Los acusaron de ateístas para congraciarse con la Iglesia, mas no pudieron persuadirlos de su error, ya que no tenían la facultad, ni un método de lógica, ni filosofía que valiera para apagar las otras." ${ }^{\prime 76} \mathrm{El}$ penitente de los jesuitas intervino preguntando "si hubo alguien que convenciera a los cartesianos". La respuesta del contrario fue: "en física fueron convencidos por los ingleses, quienes les mostraron las leyes del movimiento en los vértices, en materia de luz y en muchas otras cosas. Posteriormente, los seculares se desengañaron de la filosofía de Descartes y casi todos se volvieron seguidores de Newton. Así, surgió en Inglaterra otro autor llamado Locke, escéptico y epicúreo, que tuvo muchos seguidores porque proponía una filosofía tan superficial y sensible cuanto falsa. Al final -añadió- los estudiosos han andado de acá para allá, a tientas y cometiendo nuevos errores, hasta que todos se han convertido en poco menos que escépticos. A ninguno de estos abusos importantísimos han sabido dar solución los escolásticos y todo eso ha sucedido por la falta de un conocimiento verdadero." 77

Finalmente, el joven jansenista preguntó si alguien había convencido a los cartesianos en materia de metafísica. El contrario de los jesuitas respondió que: "mientras la Escolástica seguía en el caos y la confusión, la cartesiana estaba en pie. La filosofía de Descartes había sido impugnada por Gisbertus Voetius (1589-1676) y muchos otros, aunque ninguno había tomado la vía justa para contradecirla completamente. Voetius refutó únicamente la distinción real que Descartes hizo en la sexta meditación, pero no descubrió la falacia que se encontraba en el método."78

Éste es el único momento en las Cartas en el que Doria tomó la palabra en primera persona para argumentar que

76 "Il Vostro Contrario: trattarono da Atei i Renatisti, gli accusarono a Santa Chiesa, ma convincergli non seppero mai, perche Renato nelle sue meditazioni procede con método di apparente Geometria, onde Gesuiti, che quella non sanno, non mai potevano convincergli, alla perfile essi sanno gridare agli Ateisti a fine di farsi merito con Santa chiesa, ma poscia di convincergli d'errore non hanno la facoltà, e ciò perche non hanno nè metodo di logica, nè Filosofia, che vaglia ad appagar altri, che gli Sciocchi." Doria, P. M. 1731: 341.

77 "... gli Inglesi hanno convinto d'errore Renato nella Fisica, perche il Signor Newton gli hà convinti d'errore nelle leggi del moto nei Vortici, nella materia della luce, ed in molte e molte altre cose; onde poi i Secolari si sono un pò disingannati della Filosofia di Renato, e si sono quasi da tutti fatti Newtonisti; indi è sorto in Inghilterra un'altro autore nomato Looch scettico ed Epicureo, il quale ancor'esso hà avuto seguito, perche propone una Filosofia tanto superficiale, e sensibile, quanto falsa: alla perfine i Scolari sono andati di quà e di là brancolando da lor medesimi e sempre in nuovi errori cadendo, sino a tanto, che in oggi cosa sono divenuti poco men, che tutti Scettici, nè a questi importantissimi abusi hanno mai saputo gli scolastici dar reparo, e ciò è avvenuto, perche essi non hanno vera, e constante Sapienza." Doria, P. M. 1731: 341-42.

78 Doria, P. M. 1731: 242-243 "él había impugnado a Descartes en algebra", esto es, en sus propios términos, "asumiendo la tarea que los jesuitas no pudieron hacer". A este punto, Doria pidió a los participantes leer sus Matemáticas impresas en Venecia en 1726 y su duplicación del cubo traducida al latín, publicada ahí mismo en 1730. En estas obras, explica que Descartes se había equivocado en las curvas de Apolonio, las cuales afirmó, contra la opinión de matemáticos antiguos, eran líneas geométricas. Allí mismo, Doria invitó a los asistentes del debate a leer su libro Discorsi Critici (1724), donde ellos podrían ver que él demostró la falsedad de Descartes, la de Locke, y todo el conocimiento de los filósofos modernos, además de haber demostrado la utilidad de la filosofía de Platón, la cual él creía que era la más apropiada para el conocimiento humano y más aún para la religión cristiana. Asimismo, afirmaba que era posible corroborar en todos sus libros cómo había revelado los fines de los jansenistas e impugnado sus falaces y perniciosas máximas. ${ }^{79}$

"Señor Paolo, es verdad lo que dice, pero usted no ha impugnado la filosofía Escolástica - argumentó el contrario de los jesuitas." Doria asintió agregando que "a pesar de que nunca la había aprobado, no se había pronunciado anteriormente por respeto a una Compañía que tenía mucha autoridad en el mundo y porque, habiendo tomado la empresa contra los modernos, le parecía poder disimular su desprecio por la Escolástica, pero, un hombre como él, que profesaba honor y sinceridad, no podía hacerlo sin ofender la verdad, ni su nombre. Por otra parte, afirmaba que mientras convencía del error a los filósofos modernos contrarios de los jesuitas, a los cuales éstos no habían sabido impugnar, esperaba que su obra fuese grata a la Compañía de Jesús." ${ }^{80}$ A esto, el contrario preguntó: "si los jesuitas habían agradecido las obras de Doria." Él respondió que "sí porque eran contrarias a sus opositores, pero ellos siempre mantuvieron distancia de él, distancia de maestros, ya que lo consideraron un seguidor de su doctrina, que había aprendido y respondido bien a los modernos; sin embargo, los jesuitas creían ya haber impugnado previamente a sus detractores." ${ }^{81} \mathrm{Al}$ final, el contrario de los jesuitas preguntó a Doria “¿cuál fue, entonces, su utilidad al refutar a los cartesianos?" A lo que Doria respondió: "haber sido robado por los jesuitas. Él creía que éstos eran Amicis frigidi, et inimici potentes, pero no que fueran amigos traidores. Para él, los miembros de la Compañía de Jesús se habían comportado como el peor de los bandidos. En el reino de Nápoles, robaban y asesinaban a todos, sólo cuidaban a los amigos, los defendían y los ayudaban en lo que les hiciera falta, pero en Génova le hicieron ver que tratarían igualmente a amigos que a enemigos." ${ }^{82}$

\section{Ibídem.}

80 Doria, P. M. 1731: 343.

81 "E qui disse il Vostro Contrario: gradirono poi i Gesuiti le Vostre Opere? Ed io risposi sì, perche erano contrarie ai loro Contrarj, me però le gradirono sempre conservando anco con me l'autorità di Maestri; e come di grazia? Disse il vostro contrario. Et io: ragionavano di me come di un seguace della loro dottrina, il quale avea ben saputo profittare di quella, per modo tale, che avea ben risposto a quei Moderni, che però essi avevano già sconfitti." Doria, P. M. 1731: 343.

82 Doria, P. M. 1731: 344. 
A continuación, el penitente de los jesuitas preguntó a los demás participantes del diálogo qué filosofía creían ellos que restituiría al mundo la ciencia y las buenas costumbres. Preguntó también si acaso creían que algún filósofo moderno, como Descartes, Gassendi o Locke, podría cumplir sendo cometido. El contrario a los jesuitas respondió que: "no elegiría a ninguno de los modernos porque todos ellos caían siempre, o en la secta de los epicureístas o en la de los escépticos. Pensándolo detalladamente, respondió que Platón sería su opción, ya que éste, aunque era un filósofo gentil, había enseñado ideas verdaderas sobre las virtudes de la justicia, la fortaleza, la templanza, la prudencia, la virtud heroica y todo lo que en el mundo no sólo no se oponía a las verdades de Dios, sino que había sido revelado a los cristianos. Dicho en una frase: porque éste no sólo permitiría a los hombres alcanzar una verdad estable, sino que les permitiría desarrollar una filosofía moral". ${ }^{83} Y$ con este comentario se cerró la discusión concluyendo la poca utilidad de la lógica de los jesuitas para la Iglesia y para el mundo. $^{84}$

\section{SOBRE EL MÉTODO}

La crítica de Doria al método de los jesuitas es acaso la más importante de todas sus observaciones, ya que es la que lo lleva a concluir que probabilística ya no podía ser el método para impartir justicia y mucho menos la base de un sistema moral. Los hombres de letras nunca como en ese momento eran conscientes de que la verdad estaba fuera de su alcance. Doria afirma que si algo tenían claro los filósofos modernos era la imposibilidad de alcanzar la verdad, lo bueno y lo justo, que es sólo accesible a Dios. Esto es así, debido a la naturaleza pasional de los hombres, o lo que se conoce en la literatura de derecho natural moderno como los efectos de la caída del paraíso, y que afectan directamente la felicidad y la sociabilidad de los hombres en el estado de naturaleza. O dicho de otro modo, Doria relata en sus Cartas que en esta época se extendió el lugar común de que los hombres no eran racionales, felices, sociables por naturaleza. En palabras de Malebranche: los hombres son la parte más infeliz de la creación de Dios. ${ }^{85}$ Ahora bien, gracias a las enseñanzas de Descartes se pensaba entonces que los hombres podrían llegar a corregir esta condición a lo largo de su vida, a través de un proceso de educación.

En la filosofía política de Doria, el pasaje sobre el estado de naturaleza es muy breve y casi podríamos decir que hubiera querido evitarlo, que le resultaba incómodo. Sin embargo, es importante entender que Doria sí hace referencia a las características psicológicas de los hombres después de la expulsión del paraíso y que, debido al pecado original de Adán y Eva, los hombres fueron reducidos a una condición similar a la de las bestias. Luego de la caída, los

83 Doria, P. M. 1731: 320-321.

84 Doria, P. M. 1731: 344.

85 Malebranche, N 1764 [1963] De la Recherche de la Verité, en Oeuvres Complètes de Malebranche, Rodis-Lewis G. (ed.). I. Paris. Doria cita varias veces este pasaje de Malebranche en distintas obras, entre las más importantes cfr. Doria, P.M. 1710. hombres se habían convertido en seres irracionales e incapaces de entender las leyes naturales o los designios de Dios. Debido a la expulsión del paraíso los hombres quedaron reducidos a su condición pasional, bestial, y la verdad, lo que es bueno y justo para ellos y su prójimo, estaba fuera del alcance de su entendimiento. Doria argumenta en algunos textos que luego de la caída, los hombres actúan bajo el efecto de la fantasía y ninguna de sus acciones en estas condiciones puede ser considerada como un acto libre. En la filosofía política de Doria, los hombres pueden superar su condición caída a través de la educación, pero el conocimiento perfecto queda fuera de su alcance. Debido a su infelicidad la única posibilidad de alcanzar la salvación es a través de la unión a la Iglesia, la cual es la única que puede guiarlos por los senderos de los sacramentos hacia Dios. Aun así, los cristianos saben que la salvación no es para todos, sino que está reservada para aquellos que obtengan la gracia de Dios. Ahora bien, la felicidad perfecta, que es un estado de contemplación permanente de la perfección de Dios, y que conduce sin duda a la salvación, son temas que no le interesan a Doria. De hecho, su mérito es precisamente la secularización de la discusión sobre la felicidad en Nápoles, ya que a partir de su obra La vita civile (1709) se debatirá este tema en términos humanos. ${ }^{86}$ Una década más tarde, el filósofo napolitano Giovan Battista Vico llevaría a cabo un intento similar, alcanzando un resultado acaso menos secular al doriano y con características distintas en su Ciencia Nueva (1725), pero que debe considerarse en esta línea, como un intento de la secularización de los fundamentos de la política. ${ }^{87}$

En 1709 Doria no estaba interesado en discutir el pasaje del estado de naturaleza, esto es, la fundación del Estado o de la sociedad civil. Su interés era discutir a partir del momento en que los hombres ya se habían unido en sociedad. Además, le interesaba discutir el momento en el que se encontraban los hombres en el proceso de civilización en las primeras décadas del siglo XVIII. En su opinión los hombres se habían civilizado ciertamente gracias a ese largo proceso recorrido a lo largo de la historia de la humanidad y estaban lejos del punto de partida. El conocimiento humano, aunque imperfecto, había mejorado, sobre todo en el último siglo, pero debido a su condición los hombres estaban lejos de la verdad, de lo que era bueno y justo, y tenían que contentarse con encontrar la causa más probable en los juicios y en los tribunales. ${ }^{88}$ El énfasis de Doria en las Cartas se sitúa, por un lado, en el hecho de que el método de la casuística era defectuoso y, por otro, en la irracionalidad de los hombres. Estos elementos por lo demás son constantes a lo largo de toda su obra. En repetidas ocasiones, el filósofo genovés

86 Doria, P. M. 1710.

87 Vico, G. B. [1725] 1931. Scienza nuova prima. Principii di una scienza nuova d'intorno alla natura delle nazioni. Fausto Nicolini (ed.). Bari: Laterza. Sobre un estudio de la felicidad en estos autores LunaFabritrius, A. "The Secularization of Happiness in Early Eighteenth Century Italian Political Thought: Revisiting the Foundations of Civil Society" en Trust and Happiness in the History of European Political Thought. Kontler, L. And Somos M. (eds.). (en prensa).

88 "L'opinione probabile si debe in buona Logica cercare, a cagione che la nostra mente non può conoscere il vero, ch'è uno in tutte le cose..." Doria, P.M. [1737] 1982: 408. 
afirma que sin un razonamiento humano perfecto tampoco sería posible alcanzar un sistema de justicia perfecto. ${ }^{89}$

Pero vamos por partes, la historiografía sobre tradiciones de derecho natural moderna, como es denominada en inglés, que inició según algunos autores con Hugo Grotius, Thomas Hobbes, John Locke, Samuel Pufendorf, etc. ${ }^{90}$ - salvando la debida distancia que existe entre todos ellos-, indica que uno de los elementos característicos de estas teorías es que tienen como objeto principal proporcionar explicaciones racionales sobre la fundación del Estado moderno ${ }^{91}$ y que más tarde hubo un cambio de interés hacia la organización de la sociedad, como en el caso de Pufendorf. ${ }^{92}$ Otros autores han afirmado que algunas de estas características aparecieron incluso antes en la obra de Francisco Suárez (1548-1617), ${ }^{93}$ mientras que otros estudiosos han encontrado cambios importantes en autores anteriores a este último. ${ }^{94}$ Nos han indicado que las diferencias en las teorías de estos autores y las católicas radican en los efectos de la caída, ${ }^{95}$ ya que las teorías católicas originalmente eran aristotélicas y tenían como punto de partida al zoon politikon, mientras que en las protestantes el efecto era mayor, como ejemplo véase el caso de Hobbes y Spinoza donde los efectos son, podríamos decir, dramáticos..$^{96}$ La literatura nos ha indicado que en este pasaje introducido por Hobbes a su teoría política radicaba su separación definitiva del Aristotelismo y el completo abandono de su concepción del hombre sociable. ${ }^{97} \mathrm{Y}$ aún más, se ha afirmado que en la introducción de este pasaje radica también la secularización de la política, que siguieron más tarde otros teóricos del derecho natural protestante. Se dice que se produce la secularización porque, visto que la razón comunica a los hombres con su creador al ser irracionales, se rompe el puente que comunica el intelecto humano con su creador. El resultado es que los hombres no pueden apreciar la perfección de Dios, así como tampoco entender y llevar a cabo las leyes naturales básicas que él les ha dado y, por tal motivo, a ellos no les queda más remedio que hacerse cargo de la organización de

89 Esta opinión de Doria fue compartida por muchos napolitanos a lo largo del todo siglo XVIII hasta Gaetano Filangieri en su Ciencia Nueva.

90 Tierney, R. 1989 "Origins of natural rights language: Texts and contexts, 1150-1250" History of Political Thought 10: 615-646 y 2006 "Dominion of Self and Natural Rights before Locke and after" en Korkman, P. y V. Mäkinen (eds.). Transformations in Medieval and Early-Moern Rights Discourse: 173-203 NL: Springer; Brett, A. 2006 "Politics, Right(s) and Human Freedom in Marsilius of Padua" en Korkman P. 2006: 96-116.

91 Tuck, R. 1979, Natural rights theories, Cambridge: CUP y Haakonssen, K. 1996 Natural law and moral philosophy: from Grotius to the Scottish Enlightenment, NY:CUP.

92 Hont, I. 2005. Jelousy of Trade. International Competition and the Nation-State in Historical Perspective, Cambridge: CUP y Saastamoinen, K. 1995. The Morality of the Fallen Man. Samuel Pufendorf on Natural Law. Helsinki: SHS.

93 Cfr. Haakonssen, K. 1996.

94 cfr. Comparato, V. I. Aquí mismo.

95 Para muestra un botón, mírese el título de la obra de Saastamoinen, K. 1995 y Coleman, J. 2006 "Are there any Individual Rights on Only Duties? On the Limits of Obedience in the Avoidance of Sin According to Late Medieval and Early Modern Scholars' en P. Korkman 2006: 3-36.

96 Esto no quiere decir que no hubiera teorías de derecho natural protestantes de corte aristotélico como sí las hubo en Alemania.

97 Tuck, R. 1996. "Hobbes' Moral Philosophy" en T. Sorell (ed.). The Cambridge Companion to Hobbes: 184-186. Cambridge, CUP. la política y la sociedad. ${ }^{98}$ Es decir, éstos se vuelven temas exclusivamente humanos. Durante años hemos aprendido que en esto radicaba la "modernidad" de las teorías de derecho natural protestante iniciado con Grotius en De Jure Belli ac pacis (1625). Y con el tiempo también hemos entendido que el fundador de esa tradición fue Pufendorf, quien puso el énfasis en "las diferencias" de las teorías de Grotius y Hobbes respecto del derecho natural neo-escolástico para luego inscribirse él mismo como parte de esa tradición.

La casuística en escrutinio en las Cartas de Doria es un método para ejercer justicia aplicado por jueces, cuya psicología moral sufría graves efectos causados por la expulsión, es decir, de todos los efectos del pecado original o la caída. Enfatizado de este modo, los efectos neo-agustinianos en la filosofía política de Doria son muy cercano a los que habían sido condenados por Trento en 1563 y perseguidos a través de la obra de los jansenistas principalmente. Sin embargo, lo que llama la atención es que Doria no era un jansenista neoagustiniano, al menos eso es lo que aclaró en sus Cartas; tampoco quería ser asociado con los investiganti, y, menos aún, con los teóricos de derecho natural protestante. Para evitar toda asociación, un par de años después de escribir estas Cartas refundó, junto con Giovan Battista Vico, l'Accademia degli Oziosi que fue un refugio de los antiguos o los antimodernos en Nápoles en 1733. Ahora bien, a pesar de que no existen estudios sistemáticos que comparen los cambios de estos autores en ese periodo, se puede afirmar que la fundación de esta academia no significó el regreso de Doria o Vico a concepciones más felices de naturaleza humana, por lo cual la asociación con los antiguos debe buscarse en otro lado.

Pero lo más sorprendente es que los autores del método de justicia en escrutinio eran los jesuitas, "supuestos" defensores a ultranza de las teorías aristotélicas y la sociabilidad de los hombres. En principio se suponía que deberíamos encontrar en sus obras - también con grandes diferencias entre los autores - defensas a la capacidad racional de los hombres y sobre todo al libre albedrío. ${ }^{99}$ Sin embargo, aunque Doria había sido educado por los jesuitas, como todos los aristócratas de su época y conocía la Escolástica, la discusión que aquí presenciamos se centra en los defectos de la psicología moral de los hombres, misma que los inhabilita para impartir justicia. En las Cartas, discute sólo brevemente en algún momento el libre albedrío, pero el énfasis está en la construcción de la felicidad humana. Finalmente, en la evaluación de su relación con los jesuitas, es importante saber que al final de su vida su magnum opus, Idea di una perfetta Repubblica (1753), la cual debía ser publicada de forma póstuma, fue condenada al fuego por la Inquisición. Esto es, a pesar de los esfuerzos de Doria a lo largo de su vida, tanto su filosofía política como su análisis de la Escolástica enfatizan los efectos de la caída y eso lo hace más cercano a la línea neo-agustiniana. Esto es, independientemente de sus intentos por tomar distancia de los jansenistas, la psicología

98 Haakonssen, K. 1996.

99 Brett, A. 1997. Liberty, Right and nature: Individual rights in later scholastic thought. CUP y para un estudio sobre este tipo de grupos neo-aristótelicos pero protestantes cfr. Darwall, S. 2006. "Norm and Normativity" en Haakonssen K. (ed.). The Cambridge History of Eighteenth-Century Philosophy: 987-1025. CUP. 
moral de los hombres en la filosofía política de Doria era muy similar a lo que Trento había condenado.

Pero Doria, ha quedado establecido, no era un jansenista, entonces el probable es que el hombre, definido como ser pasional, había tomado un lugar central en el Nápoles de la época y paulatinamente se convirtió en un lugar común del que Doria y sus contemporáneos eran participes, ya fueran cartesianos-jansenistas, atomistas-deístas 0 , jesuitas de finales del siglo XVII y principios del siglo XVIII. Recordemos que estas Cartas estaban dirigidas al General de la Compañía de Jesús. ${ }^{100}$ Así, Doria nos muestra en este documento que esta definición de naturaleza humana era más extendida de lo que la historiografía ha notado hasta ahora y tal vez vale la pena comenzar a pensar que su gran difusión se debió a que éste era un enfoque científico del hombre. Acaso sea más preciso decir: producto de la revolución científica del siglo XVII en Nápoles y que, si bien tuvimos noticia en el presente a través de autores que cultivaron la filosofía de Descartes, Spinoza y Hobbes, ésta tuvo que ver al mismo tiempo con otros factores como el declive de la Escolástica y la visión aristotélica del hombre sociable o el zoon politikon. ${ }^{101}$

En las Cartas de Doria incluso el hombre sabio era incapaz de escapar de su condición caída y, como los demás, estaba abocado a la búsqueda de su propio interés y, en caso necesario, decidiría e impartiría justicia buscando la causa más probable y de acuerdo con su propia utilidad. ${ }^{102}$ Por tanto, concluye que la justicia resultante de un sistema como el de los jesuitas sería siempre una opinión probable y dejaría dudas sobre su verdadera naturaleza justa, esto es, todos los hombres dudarían hacia qué lado se inclinaría la balanza de la justicia. ${ }^{103}$

En adelante, la crítica de Doria al método se convierte en una suerte de denuncia por el abuso de recursos legales en los tribunales para apropiarse de herencias y demás bienes privados de sus penitentes. ${ }^{104}$ Para el filósofo genovés, los jesuitas han usado las leyes a su antojo en Nápoles, en Génova, y en cualquier parte del mundo gracias a su "método sofisticado". Y si los jesuitas se han valido de los remedios legales que dan las leyes era debido a "la sofística, que es hija del amor propio". ${ }^{105}$ Con esta frase Doria concluía volviendo

100 No se quiere afirmar que los jesuitas hayan adoptado también concepciones neo-agustinianas de naturaleza humana, pero que merecería la pena un estudio sistemático de su obra en este periodo.

101 Malcolm, N. 2002. Aspects of Hobbes, Oxford: Clarendon Press.

102 Doria, P. M. 1731: 272.

103 Ibidem.

104 Cfr. Doria, P. M. 1728 y 1731: 283. “Ex Operibus eorum, cognoscentis eos, (Aquinas)...l'Amor di Dio, e la Carità verso il Prossimo non son eglino una cosa istessa?... come possono i Gesuiti amare il loro prossimo, e tutt'ad un tempo spogliare gli Eredi delle Eredità, che a loro appartengono di diritto, e predersi quell'immensi legati, che le Famiglie rovinano? Come possono nei Tribunali usar quelle Calummie, che usano? E quì il Vostro Penitente: In quanto alle Eredità, o ai legati, che ricevono, queste sono per lo più spesso meglio impiegate nei Gesuiti, che negli Eredi, e che in altri, perche i Gesuiti fanno infiniti beni al Pubblico con le Prediche, con le Confesioni, con le Missioni, e con tante, e tante opere pie che fanno; dobbiamo noi dunque contribuire al mantenimento di questa utilissima Compagnia; In quanto poi alle calumnie, ...che danno nei Tribunali, queIlo non sono calumnie, sono rimedj legali, che dà la legge, perciò santamente se ne possono servir come gl'altri." Doria, P. M. 1731: 296-97.

105 El concepto de amor propio en Doria tiene que distinguirse del de Malebranche. Para un estudio sobre esto cfr. Luna González, A. 2009. a poner el acento en la naturaleza pasional de los hombres, los cuales buscan exclusivamente su propio interés, su propia utilidad o amor propio, por ponerlo en el concepto corriente de la época, y sin considerar el bien común del público o la justicia. ${ }^{106}$

Para Doria lo más problemático de los jesuitas era que estos habían abusado de su sistema de justicia para beneficiar a sus allegados, y lo hicieron de forma tal, que no sólo echaron por tierra la credibilidad de su método sino que también desprestigiaron su moral, la cual en ese momento demostraba ser más "fácil de seguir que la de los gentiles", ya que la historia había revelado que gentiles como Platón o Sócrates nunca usaron la justicia en su beneficio. ${ }^{107}$ Este comentario es de doble filo y se refiere a los temas más controvertidos del pensamiento político en la era de la Contrarreforma, a saber, los delicados debates sobre las virtudes de los paganos y qué comunidad religiosa podría ser la mejor guía moral, no para alcanzar la salvación, sino para cohesionar a los hombres en la vida civil. Doria repasa con cuidado todas las posibilidades. ${ }^{108}$ Entre las opciones a la mano, Doria afirmaba que los capuchinos tenían fama de tener reglas más estrechas que los jesuitas, que como ya se sabía eran "demasiado suaves y faltos de autoridad". En este texto como en otros, Doria comenta varias veces que los jesuitas estaban especialmente interesados en controlar las máximas referentes a la ciencia y al hacer eso habían descuidado completamente las del gobierno y la política. ${ }^{109}$

Ahora bien, para el filósofo genovés el problema radicaba en que en la base de este sistema probabilístico estaba la virtud de la opinión probable que dependía de la buena dirección de la voluntad. ${ }^{110}$ Por ejemplo, mientras que los jesuitas destruían a los que se oponían a su ciencia, su moral y sus costumbres, en virtud de la opinión probable y de la buena dirección de la voluntad, cometían pecados sin aceptar que lo hacían. ${ }^{111}$ Así, la discusión sobre el método para impartir justicia concluía afirmando que la degradación del método era tal que éste necesitaba ser sustituido.

106 Doria, P. M. 1731: 297 y Doria [1737] 1982: 314-315.

107 Doria, P. M. 1731: 277.

108 "Ancora che questo argumento potese essere più probabile del mio, è cosa certa, che i Padri Gesuiti possono seguire il meno probabile, lasciando il più probabile, perchè è massima certa dei nostri Morali, che quando ciò ridonda in nostro utile, possiamo anteporre l'argomento meno probabile al più probabile". Doria, P. M. 1731: 272.

109 Doria, P. M. 1731.

110 "I Gesuiti non giustificano i peccati, ma con la loro Morale fa sì che quelle istesse cose, le quale fatte in un certo modo, e con una tale intenzione sono peccati, fatte poi in altro modo, e con altra Intenzione non siano più peccati, Oh! Questa dottrina, che a quel che vedo, Voi non sapete, è la gran dottrina della direzione dell'intenzione, e dell'equivoco; con questa si può dire la bugia senza mentire, si può ingannare il prossimo senza ingannare, basta saper ben dirigere l'intenzione, e ben maneggiare gli equivoci." Doria, P. M. 1731: 283.

111 "Mentre i Padri perseguitano, ed annientano quelli, che si oppongono alla loro Scienza, alla loro Morale, ed ai loro costumi, non odiano quei loro contrarj quantunque facciano tutto quello, che farebbero, se l'odiassero, ed in questa guisa non tolgono il peccato dell'odio, come voi dite, ma in virtù dell'opinione probabile e della buona direzione della Volontà, fanno senza commetter peccato d'odio, quello stesso, che farebbero, se odiassero; alle per fine credetemi, che la Morale dei Gesuiti è ingegnosissima, e nello stesso tempo Santissima." Doria, P. M. 1731: 281. 


\section{LA TEOLOGÍA}

Gracia eficaz y el libre albedrío son, sin duda alguna, los temas más complejos de la Contrarreforma y el núcleo del debate entre jesuitas y jansenistas. Como se sabe, las discusiones sobre el libre albedrío y Pelagio eran temas prohibidos en la época, pero sin duda alguno los más fascinantes. Por ello, Doria parece querer evitarlo en la medida de lo posible; sin embargo, no logra pasarlo por alto. Al iniciar su comentario, el contrario de los jesuitas propuso en el dialogo conceder por ciertas las proposiciones de la Iglesia y afirmar con ella que todo depende de la gracia divina: Dios en virtud de su sobrenatural omnipotencia dio la libertad a los hombres, no obstante, ellos no pueden entender el origen de esa libertad. Si uno entra en materia de gracia y libre arbitrio, que son temas incomprensibles, cae inmediatamente en un precipicio sin salida porque no es posible entender cómo funcionan y no se podría discutir sobre ellos como lo hicieron Pelagio y Jansenio. ${ }^{112}$ Ante esto, el joven jansenista respondió en el debate que "las proposiciones que se atribuyen a Jansenio las refutan incluso ellos y que en ese momento del siglo XVIII los jansenistas niegan rotundamente que esas proposiciones hayan partido de él." ${ }^{\prime 13}$

En este diálogo sobre la teología, el joven jansenista participa de forma más activa para puntualizar que los jesuitas han argumentado la existencia de una gracia suficiente, la cual no basta por sí misma puesto que la gracia de Dios es siempre eficaz. Dios es omnipotente y su gracia no puede dejar de operar en ningún momento. Recordó además, la sentencia de Dios a San Paolo: Durum est contra stimulum recalcitrare. A lo que el contrario de los jesuitas respondió: "¿cree usted que los hombres no pueden oponer el libre albedrío a esa gracia eficaz?". Y el joven jansenista respondió que: "de poderse, se puede; sin embargo, no ha habido quien haya podido resistirse a la gracia eficaz de Dios". El contrario de los jesuitas intervino: "entonces ¿el libre albedrío es una libertad que no es libertad? No cabe duda que ustedes ríen de nosotros presentándonos, como hacen los jesuitas, una gracia que no basta porque no es suficiente y ustedes una libertad, que no es libre". Ante esto, el joven jansenista aseguró con celo que ya era suficiente, que el tema era prohibido y que no se podía entrar en temas de Pelagio, como habían hecho los jesuitas. A pesar de ello, el contrario lo exhortó a explicar su afirmación. Por lo que el joven se apresuró a decir que había sido Luis de Molina quien impíamente dijo que Dios solamente preveía nuestras acciones y que había dado a todos una gracia suficiente para poder obrar independientemente de él. "Como ustedes saben -refiriéndose a los participantes de la discusión-, esta proposición implica lo mismo que ha dicho Pelagio, esto es, que los hombres pueden obrar independientemente de Dios". Entonces, el contrario de los jesuitas aprovechó la ocasión para preguntar su posición respecto de la gracia coadyuvante de los semipelagianos. El joven jansenista respondió que la gracia coadyuvante era absolutamente inaceptable

\footnotetext{
112 Doria, P. M. 1731: 309-310.

113 Doria, P. M. 1731: 310.
}

puesto que no estaba de acuerdo en admitir otra gracia que no fuera la eficaz, la cual es la única que actúa sobre los hombres. ${ }^{114} \mathrm{El}$ contrario de los jesuitas respondió a esto que: "la gracia eficaz que mueve a los hombres se parece en un punto al fato de los griegos y al destino de los gentiles, ${ }^{115}$ porque bajo el manto de un aparente rigor, lo que hace es quitar toda obligación a los actos de los hombres, imputando todo a la gracia eficaz." ${ }^{116}$ Por otra parte - añadió el contrario-, dar todo el arbitrio a los hombres, como había hecho Pelagio, ofendía la omnipotencia de Dios y, desde su perspectiva, no estaría de más intentar buscar una vía distinta. El joven jansenista respondió: "lo que quiere usted es hacerse semipelagiano y eso sí que está prohibido". Con esta frase se cerró el debate sobre estos temas.

\section{CONCLUSIÓN}

La expresión anterior es acaso la más adecuada para cerrar este artículo porque es la que mejor refleja la intención de Doria, esto es, buscar, experimentar hasta dar con una opción moral viable para la vida civil del abanico que se abría entre los principios jesuitas y jansenistas. En estas Cartas todo indica que Doria quería hacer manifiesto que la moral que profesaban los jesuitas era corrupta, debido a que su método, su filosofía y su teología consecuentemente, no servían más, y lo hace, valiéndose del lenguaje de la época: el del derecho natural.

En este texto del filósofo genovés subyace la idea de que los jesuitas tenían demasiados intereses temporales, acaso más de los que habían podido atender. Como todos los hombres, ellos buscaban su propia utilidad, sus acciones eran movidas por el amor propio. ${ }^{117}$ El problema que identifica Doria es que en la búsqueda de su utilidad, los jesuitas dejaron de proteger la autoridad del Papa, que había sido su razón de ser. El prestigio de los jesuitas declinó paralelamente a la autoridad de Roma en las cortes europeas durante la era de la Contrarreforma. Para Doria los jesuitas eran los responsables en gran medida de la pérdida de autoridad del pontífice, pero eran los responsables de su propia decadencia, la cual se debía a su incapacidad para afrontar los cambios paradigmáticos en filosofía y en ciencia. Por eso dejaron de ser autoridad en materia de moral.

114 Ibídem. En // Gesuita Tirano Doria dice que los jesuitas han sido acusados de pelagianos en materia de libre albedrio porque dan al hombre una especie de libertad casi independiente de la gracia divina y por eso, citando a Agustín Doria, afrima que: "cuando se considera infinita la omnipotencia de Dios, parece que no se pueda atribuir libertad al alma humana sin quitar algo a la divino omnipotencia, y cuando al contrario se da todo a la divina omnipotencia parece que se destruya al libre albedrio. Al final parece imposible determinar con luz natural algo en materia de gracia y libre albedrio por lo que nuestra mente debe humillarse a la decision de la Iglesia. Doria, P. M. [1737] 1982: 403-404.

115 Doria, P. M. 1731: 310.

116 En /l Gesuita Tirano, Doria afirma que con el excesivo rigor precipitan a los hombres en el ateísmo. Doria, P. M. [1737] 1982: 402.

117 La definición de amor propio de Doria es distinta de la Malebranche, véase Luna González, A. From Self-preservation to Selfliking in Paolo Mattia Doria: Civil Philosophy and Natural Jurisprudence in the Early Italianenlightenment, Tesis doctoral, Florencia, EUI, 2009, ch. 4. 
Doria reconstruye en sus Cartas el enorme vacío dejado por la Escolástica; y a pesar de que la literatura ha afirmado que éste fue llenado por los jansenistas, él argumenta lo contrario. Muestra cómo estos no podían solventarlo, al menos no en las últimas décadas del siglo XVII, pero tampoco en las primeras del siglo xVIII. La explicación cobra sentido cuando se sitúa el juicio de los atomistas-ateístas en su contexto europeo: porque los jansenistas no podían ser el instrumento de la ortodoxia y el soporte de la autoridad papal que ellos mismos habían contribuido a poner en jaque. En la era de la Contrarreforma, España se había alineado con Roma, cuya autoridad en temas temporales defendían los jesuitas y, como nos recuerda Doria, en ese contexto los jansenistas eran el apoyo de los príncipes seculares; esto es, los opositores al bloque compuesto por el Papa y el monarca español. Este último, es el frente donde los napolitanos, incluido Doria, buscaban cabida para sus filosofías políticas.

En cuanto a la formula jansenismo-cartesianismo profesada por los modernos, Doria nos cuenta como se conformó esta ecuación para el caso florentino principalmente, y a lo largo del texto en ningún momento insinúa que en Nápoles la situación fuera la misma. La explicación puede ser porque como afirma él mismo, los cartesianos sufrieron la censura de finales del siglo XVII, o simplemente porque el método cartesiano fue impugnado muy pronto por Newton, Locke y Voetius. Desde el punto de vista moral, las obras jansenistas además de que estaban prohibidas y, junto con la obra de Quesnel, habían llevado a la proclamación de la bula Unigenitius (1713), eran extremadamente rígidas; por tanto, no les parecían las más útiles para cohesionar y guiar a los hombres en la vida civil.

A esto debe añadirse que, si bien los juristas investiganti, se valieron de las teorías de derecho natural protestante, especialmente de Grotius, Hobbes, Locke, Pufendorf, etc., para apelar a los privilegios del reino de Nápoles concedidos por los monarcas españoles, para articular una crítica a las máximas del gobierno español, durante y después de la Guerra de Sucesión Española (1701-1713), y para limitar la autoridad de su monarca, parecen no estar interesados en llevar sus argumentos hasta sus últimas consecuencias y cuestionar el origen de la misma.

Y es precisamente en este momento cuando resalta aún más la ambigüedad creada por Doria respecto al debate jesuitas-jansenistas, al mismo tiempo que cobra sentido. Por el periodo al que pertenecen las Cartas es probable que Doria aspirara a llenar el vacío paradigmático que denuncia. Eso puede explicar que no se decantase ni del lado de los modernos ni del de los antiguos, para poder acomodar su filosofía a los requerimientos políticos del momento. Ahora bien, sin importar las consecuencias de la ambigüedad, el filósofo genovés nos deja claro que en realidad las diferencias teológicas y confesionales de fondo no le importaban demasiado. ${ }^{118}$ Su formación no sólo era la de un moderno, sino que además había estado en estrecho contacto con las teorías de derecho natural protestante y conocía bien

118 Este tema es particularmente delicado en Doria, pero por su extensión debe ser tratado en otra parte. las polémicas de los autores de Port Royal. Aquí mismo nos proporciona los elementos necesarios para concluir que los fundamentos de su filosofía política son, sin duda alguna, neo-agustinianos, por el acento en la naturaleza caída, pasional de los hombres y que confiaba en la utilidad de la religión católica para no poner en riesgo los fundamentos de la política. Estos elementos alejan su filosofía política de concepciones aristotélicas de naturaleza humana profesadas por los teóricos del derecho natural escolásticos del siglo XVII, que conocía también bien. Sin embargo, aún le quedaba por discernir qué comunidad religiosa sería la más útil para la vida civil.

A este punto, debemos cuestionarnos si la falta de claridad que identificamos en la obra de Doria se debe acaso a nuestra ignorancia sobre el derecho natural católico del periodo de la Contrarreforma, porque si es cierto que la revolución científica tuvo un papel importante en su desarrollo en este periodo, entonces es viable pensar que los distintos enfoques sumados al abanico de concepciones neo-agustinianas de naturaleza humana, dieron lugar a distintas definiciones de sociabilidad que se fueron transformando a la par de los avances científicos, al menos en las academias donde convivían científicos, anatomistas y juristas. Y que estas tenían puntos de partida compartidos por sus autores, tanto protestantes como católicos durante los siglos XVII y XVIII. Esta evidencia muestra que las fronteras confesionales de las que tanto se ha discutido en las últimas décadas deben buscarse en otra parte. La popularidad de estas nuevas concepciones de naturaleza humana y sociabilidad asocial pueden deberse, al menos en el caso de la generación de Doria, al compromiso de estos filósofos con una nueva forma de pensar al hombre desde una perspectiva científica, que se va extendiendo paulatinamente hasta convertirse en un lugar común. Proceso que coincide con un regreso de la obra de Agustín. Su popularidad puede deberse a qué no era discorde con los descubrimientos de la época. Esta también puede ser la explicación del auge de teóricos de las pasiones como el mismo Maquiavelli. En cualquier caso, se hace apremiante entender la forma en que las distintas concepciones neo-agustinianas se van combinando con ese enfoque antropológico científico en el pensamiento político de la Contrarreforma en el espacio católico. En palabras de Sarpi se traduciría en, cómo la razones de ciencia predominaron sobre las razones de religión y sobre todo, cómo informaron las razones de Estado en ese periodo.

Al situar las Cartas de Doria en el contexto del juicio de los atomistas-ateístas, hemos visto surgir otros elementos clave para la historia intelectual napolitana, a saber, qué era ser cartesiano, escéptico, sensista o empiricista y epicureísta, y que estas definiciones no eran simples motes sin contenido en Nápoles, como en otros casos europeos. ${ }^{119}$ En este caso hemos visto a Doria usar estas definiciones aplicadas a los miembros de la Accademia del Cimento para refe-

119 Cfr. Anhert, T. 2009. "Epicureanism and the Transformation of Natural Law in the Early German Enlightenment" en Lifshitz A. y N. Leddy (eds.), Epicurus in the Enlightenment: Mode d'emploi: Studies on Voltaire and the Eighteenth Century: 53-68 Oxford. 
rirse a los modernos de Nápoles y hemos enfatizado las que no usa. Asimismo, aquí se ha reevaluado la importancia del juicio de los atomistas-ateístas para la historia intelectual napolitana, que fue todo menos de poca importancia dentro de la esfera de la monarquía hispánica. Finalmente, las Cartas nos han indicado el lugar que ocupaban todos estos personajes en el mapa intelectual napolitano en los albores de la llustración, el cual a su vez dependía de su ubicación en el enorme espectro creado por el debate entre jesuitas y jansenistas, en la era de la Contrarreforma.

\section{BiBLIOGRAFÍA}

\section{Fuentes primarias}

Amenta, Niccolò. 1668. II Torto e'l Diritto del non si può, dato in giudizio sopra molte regole della lingua italiana, esaminato da Ferrante Longobardi Roma.

Amenta, Niccolò. 1710. Vita di Lionardo da Capua, en Vite degli Arcadi illustri II: Roma [hay otra edición que indica Venecia, pero Nápoles].

Amenta, Niccolò. 1723 Della lingua nobile d'Italia e del modo di leggiadramente scrivere in essa non che di perfecto parlare, Nápoles.

Ballingall, George Sir. 1833. "Outlines on the Course of Lectures on Military Surgery, delivered in the University of Edinburgh" en Edinburgh Medical and Surgical Journal 40: 438-458.

Buragna, C. 1683. "Prefazione”, en Lucretius, De rerum naturae, Poesie latine e italiane.

Buragna, C. 1683. Poesie del signor. D. Carlo Buragna colla vita del medesimo. Scritta dal Signor Carlo Susanna. Nápoles: Salvatore Castaldo Regio Stampatore.

Caravita, N. 1691. Lettura sopra la concione di Marfisa a Carlo Magno de Gregorio Caloprese.

Caravita, N. [1695] 1709. Ragione a pro della fedelissima città e Regno di Napoli contr'al procedimento straordinario nelle cause del Sant'Officio, Nápoles.

Caravita, N. 1710. Niun diritto compete al sommo pontefice sul Regno di Napoli: dissertazione istorica-legale, Nápoles.

Cornelio, T. 1688 Progymnasmata phisica, Nápoles: Typographia Jacobi Raillard.

Crescimbeni, Giovanni M. 1720. Notizie istoriche degli arcadi morti I: 218 y ss. Roma: Nella Stamperia di Antonio de Rossi

D’Andrea, Francesco. Avvertimenti ai nipoti.

De Cristofaro, G. 1700. De constructione aequationum libellus, en Nápoles

De Cristofaro, G. 1720. Della dottrina Del Pezzo. Venezia.

De Cristofaro, G. 1730: Intorno al suo opuscolo sulla natura del sangue, aggiuntavi un'opinione circa il moto del cuore.

Di Capua, L. 1681. Parere.

Di Capua, L. 1683. 'Il Volubile Accademico Investigante al lettore', en Lezioni intorno alla natura delle mofete, Nápoles.
Doria, P. M. 1710. La Vita Civile di Paolo Mattia Doria distinta in tre parti, aggiuntovi un trattato della Educazione del principe, Seconda edizione dall'autore ricorretta, ed accresciuta 434. In Augusta, appresso Daniello Hopper.

Doria, P. M. 1724. Discorsi critici-filosofici intorno la filosofia degli antichi e dei moderni ed in particolare intorno la filosofia di Renato Des Cartes, Con un progetto di una Metafisica di P.M. Doria, Venezia [but Naples].

Doria, P.M. 1728. La Filosofia di Paolo Mattia Doria, con la quale si schiarisce quella di Platone, Dedicata all'Altezza Reale di Carlo Emanuele Principe di Piemonte I: IV Amsterdam [Ginebra]: Tournes.

Doria, Paolo M. [1731] 1992. "Lettere di Paolo Mattia Doria al Reverendissimo Padre Generale della Compagnia di Ges. Nelle quali dop. narratagli una nera Calunnia pratticata contro l'Autore da i Gesuiti di Genova, se gli mostra, come s. fatte calunnie usate da i Gesuiti di Genova, se gli mostra, come s. fatte calunnie usate da i Gesuiti di Genova siano caggione da i gravissimi difetti di tutta la Compagnia di suo governo, e si prega di emendargli In questi Dialoghi poi si dimostra che i RR.PP. Gesuiti sono stati di danno ugualmente alla Repubblica che a S. Chiesa", en G. Belgioioso, (ed.), Manoscritti Napoletani: Vol. I, 231-400. Napoli: Galatina C. Editore.

Doria, P.M. [1737] 1982. "Il Gesuita Tirano: Lettera II. Ad un'Amico Divisa in Capitoli Nella quale dop. essersi narrate l'Eresie, delle quali i Gesuiti sono stati accusati, si discopre una perniciossima Setta, ch'essi propagano nel Mondo in Materia di Morale; Con l'aggiunta di alcune Lettere dall'Autore indirizzate al Padre Generale della Compagnia di Ges.. Dedicata alla Serenissima Repubblica di Lucca", en Belgioioso, G. (ed). I: 401-473.

Doria, P.M. 1982 “Lettera Terza Nella quale prima si mostra, che i Pagani sono stati più esatti osservatori delle umane Virtù, che noi Cristiani; e poscia s'indaga la cagione di questo a noi vergognoso effetto', en G. Belgioioso III: 245-277.

Giannelli, Basilio. 1701. Orazione per l'elezione del gloriosissimo Filippo $\mathrm{V}$ in re delle Spagne.

Giannelli, Basilio. Educazione al figlio dell'avvocato 1781

Giannelli, Basilio. 1723. Delle rime scelte di vari illustri poeti napoletani. Firenze.

Giannone, Pietro. 1905. Vita. Nápoles.

Gimma, G. 1703. Elogi accad. Della società degli Spensierati di Rossano I: 160 y ss Nápoles. Crescimbeni, Giovanni M. 1720. Notizie istoriche degli arcadi morti I: 218 y ss. Roma: Nella Stamperia di Antonio de Rossi.

Guimenio, A. [Mateo de Moya] 1662. Adversus quorumdam expostulationes contra nonnullas iesvitarum opiniones morales, Valentiae: Typis Bernardi Nogues.

Malebranche, N. 1764 [1963] De la Recherche de la Verité, en Oeuvres Complètes de Malebranche, Rodis-Lewis G. (ed.). I. Paris.

Martini, Pietro. 1837. Biografia Sarda t. I: 17-18 Cagliari: Reale Stamperia

Mille anni di scienza in Italia. opera del Museo Galileo. Istituto Museo di Storia della Scienza di Firenze, y Addante, Luca 
Monforte, A. 1699. De syderum intervallis \& magnitudinibus opusculum cui accessit eiusdem tractatus De problematum determinatione. Nápoles: Nicolai Abri.

Monforte, A. De problematum determinatione, Nápoles.

Monforte, A.1720 De Stellarum Motibus. Opus posthumum. Florencia: Antonii-Maria Albizini.

Napoli-Signorelli, Pietro, 1811. Vicende della Cultura nelle due Sicilie. Dalla venuta delle Colonie straniere sino $a^{\prime}$ nostri giorni: 267-268 Nápoles, 2a ed.

Porzio, L. A. 1683. De Militis in castris sanitate tuenda. Nápoles.

Porzio, L. A.1701. Opuscula et fragment varia. Nápoles: Ex officinia Bulifoniana.

Porzio, L. A. 1711. Lettere e Discorsi. Nápoles: Nella Stamperia di Michel Luigi Muzio.

Porzio, L. A. 1979. Cinque lettere di Lucantonio Porzio in difesa della moderna filosofia. en M. Torini. Atti dell'Accademia di Scienze Morali e Politiche 143-171 Società nazionale di scienze, lettere e arti.

Vico, G. B. [1725] 1931. Scienza nuova prima. Principii di una scienza nuova d'intorno alla natura delle nazioni. Fausto Nicolini (ed.). Bari: Laterza.

\section{Bibliografía secundaria}

Aquarone, Alberto. 1962. "Giansenismo italiano e rivoluzione francese prima del triennio giacobino" Rassegna storica del Risorgimento: octubre-diciembre 560-624

Addante, L. 2001. 'Tommaso Cornelio (1614-1686)', en Cosenza e i consentini: un volo lungo tre millenni. Soveria Mannelli: 58 Rubbettino Editore

Amabile, L. 1829. II Santo officio della Inquisizione in Napoli: narrazione con molti documenti inediti, Città di Castello: S. Lapi.

Anhert, T. 2009. "Epicureanism and the Transformation of Natural Law in the Early German Enlightenment" en Lifshitz A. y N. Leddy (eds.), Epicurus in the Enlightenment: Mode d'emploi: Studies on Voltaire and the Eighteenth Century: 53-68 Oxford.

Belgioioso, G. 1992. Manoscritti Napoletani Napoli: Galatina Congedo Editore, 5 vols.

Belgioioso, G. 2012. "Paolo Mattia Doria” en Dizionario biografico degli Italiani: ad vocem Roma: Istituto della Encliclopedia Italiana.

Borreli, 1981. A. "L'apologia in difesa degli atomisti di F. D’Andrea". Filologia e Critica VI: 259- 267

Brett, A. 1997. Liberty, Right and nature: Individual rights in later scholastic thought. CUP

Brett, A. 2006 "Politics, Right(s) and Human Freedom in Marsilius of Padua" en Korkman P. 2006: 96-116.

Cappello, C. 1946. G. B. Vico e il processo contro ateisti napoletani, in Salesianum VIII

Capone, Braga, G. 1920. La filosofia francese e italiana del settecento II: 6 Arezzo: Pagine Critiche.
Carini, I. 1891. L'Arcadia dal 1690 al 1890 I: 497 y ss. Roma: Filippo Cuggiani.

Colapietra, R. 1961. Vita pubblica e classi politiche del viceregno napoletano (1656-1734) Roma: Edizioni di Storia e Letteratura.

Coleman, J. 2006 "Are there any Individual Rights on Only Duties? On the Limits of Obedience in the Avoidance of Sin According to Late Medieval and Early Modern Scholars' en Peter Korkman 2006: 3-36.

Comparato, V. I. 1970. G. Valletta: 143-48 Napoli.

Conforti, M. 2007, "chapter 4" en Ole Peter Grell y Andrew Cunningham (eds.). Medicine and Religion in Elightenment Europe. England: Ashgate Publishing.

Cortese, N. 1923. I ricordi di un avvocato napoletano del Seicento, Francesco D’Andrea. Napoli: L. Lubrano.

Darwall, S. 2006. "Norm and Normativity" en Haakonssen K. (ed.). The Cambridge History of Eighteenth-Century Philosophy: 987-1025. CUP.

De Giovanni, B. 1970. La vita intellettuale a Napoli en Storia di Napoli. VI 1. Nápoles

De Giovanni, G. M. 1954. "Il Giansenismo a Napoli nel secolo 18", Asprenas. Napoli

Favino, F. 2011 "Antonio Monforte" en Dizionario biografico degli Italiani, Trecani ad vocem.

Fisch, Max H. 1953. 'The Academy of the Investigators". en Sciene, Medicine and History: 521-526 London: Oxford University Press.

Galasso, G. 1970. "Napoli nel viceregno spagnolo dal 1648 al 1696". Storia di Napoli VI.

Galasso, G. 1972. "Napoli nel vice regno spagnolo 16961707". Storia di Napoli VII.

Garin, E. 1966. Storia della filosofia italiana. Turín: Einaudi.

Giannantonio, P. 1962. L’Arcadia napolitana. Nápoles: Liguori

Giovanni, A. 1812. Dell'Origine de' progressi e dello Stato attuale d'ogni letteratura t. 14 Prato: Stamperìa di Vincenzo Vestri.

Haakonssen, K. 1996. Natural law and moral philosophy: from Grotius to the Scottish Enlightenment. NY:CUP.

Hont, I. 2005. Jelousy of Trade. International Competition and the Nation-State in Historical Perspective, Cambridge: CUP

Jannaco, C. y M. Capucci, 1963. I/ Seicento. Milano: F. Vallardi.

Jemolo, Arturo C. 1928. Il giansenismo in Italia prima della Rivoluzione Bari: Laterza \& figli.

Luna-Fabritrius, A. "Happiness in Early Eighteenth Century Italian Political Thought: Revisiting the Foundations of Civil Society" en Trust and Happiness in the History of European Political Thought. Kontler, L. And Somos M. (eds.). (en prensa).

Luna González, A. 2009. From Self-love to Self-liking in Paolo Mattia Doria: Civil Philosophy and Natural 
Jurisprudence in the Early Italian Enlightenment, Doctoral thesis, Florencia: European University Institute.

Malcolm, N. 2002. Aspects of Hobbes, Oxford: Clarendon Press. Malcolm, N. 2002. Aspects of Hobbes, Oxford: Clarendon Press.

Martini, P. 1837. Biografia Sarda t. I: 17-18 Cagliari: Reale Stamperia; Giovanni. Andrés, 1812. Dell'Origine de' progressi e dello Stato attuale d'ogni letteratura t. 14: 239240 Prato: Stamperìa di Vincenzo Vestri.

Mastellone, S. 1965. Pensiero politico e vita culturale a Napoli nella seconda metà del Seicento: Firenze: D’Anna

Maylender, M. 1926-1930. Storia delle Accademie d'Italia: vol. 3-267, 526 Bologna: L. Cappelli.

Minieri Riccio, C. 1879. Cenno storico delle Accademie fiorite nella città di Napoli, en Archivio storico per le province Napolitane IV.

Mirto, A. 2012. Lettere di Antonio Magliabechi a Leopoldo de' Medici, Roma: Aracne.

Niccolini, F. 1941. Uomini di spada, di chiesa, di toga, di studio ai tempi di G.B. Vico, Milán: U. Hoepli.

Nuzzo, E. 2012. "Between Orthodoxy and Heterodoxy in Italian Culture in the Early 1700s: Giambattista Vico and Palo Mattia Doria" en Robertson J. y S. Mortimer (eds.) The inteIlectual consequences of religious heterodoxy: 1600-1750: 206-234, Leiden: Brill.

Osbat, L. 1974. L'inquisizione a Napoli. Il processo agli ateisti, 1688-1697, Roma: Edizioni di storia e letteratura.

Quondam, A. 1970. "Dal Barroco all'Arcadia”, in Storia di Napoli: IV, Napoli: Società editrice Storia di Napoli.
Quondam, A. 1979 "Minima Dandrein. Prima ricognizione sul testo dell Risposte di F. D'Andrea a B. Aletino" Rivista storica italiana LXXXII: 887-916.

Rosa M. 2014. Il giansenismo nell'Italia del Settecento: dalla riforma della Chiesa alla democrazia rivoluzionaria. Roma: Carocci.

Saastamoinen, K. 1995. The Morality of the Fallen Man. Samuel Pufendorf on Natural Law. Helsinki: SHS.

Stella, P. 1966. I/ giansenismo in Italia: I-II, Zurich: Pas Verlag.

Tierney, R. 1989 "Origins of natural rights language: Texts and contexts, 1150-1250" History of Political Thought 10: 615-646.

Tierney, R. 2006 "Dominion of Self and Natural Rights before Locke and after" en Korkman, P. y Virpi Mäkinen (eds.). Transformations in Medieval and Early-Moern Rights Discourse: 173-203 NL: Springer.

Torrini, M. 1973. "Antonio Monforte uno scienziato tra l'Accademia degli Investiganti e quella palatina di Medinaceli", en Zambelli, P. Ricerche sulla cultura dell'Italia moderna. Bari, Laterza.

Tuck, R. 1979, Natural rights theories, Cambridge: CUP y Haakonssen, Knud, 1996 Natural law and moral philosophy: from Grotius to the Scottish Enlightenment, NY:CUP

Tuck, R. 1996. "Hobbes' Moral Philosophy" en T. Sorell (ed.). The Cambridge Companion to Hobbes: 184-186. Cambridge, CUP.

Vitale, M. 1965. "Leonardo di Capua e il capuismo napoletano", in Acme XVII. 